ISSN (print) 0867-2008 / ISSN (online) 2391-75 I2

DOI: http://dx.doi.org/10.12775/OM.2019.001

\title{
JOCHEN BURGTORF*
}

Department of History

California State University

800 N. State College Blvd.

Fullerton, California 92834

United States of America

jburgtorf@fullerton.edu

\section{DIE RITTERORDEN IN DEN REGIONALEN KIRCHLICHEN STRUKTUREN DER KREUZFAHRERSTAATEN: DREI FALLSTUDIEN (AKKON, TORTOSA UND HEBRON)}

\section{KEYWORDS}

history; the Middle Ages; military orders; Crusader states; bishops; Acre; Tortosa; Hebron

\section{AbSTRACT \\ The Military Orders in the Regional Ecclesiastical Structures of the Crusader States: Three Case Studies (Acre, Tortosa, and Hebron)}

In the crusader states, the papal privileges granted to the military orders set these communities on a seemingly inevitable collision course with the local bishops who claimed that, as a result of this preferential treatment, their own income was being reduced, their jurisdiction undermined, and their spiritual activities jeopardized. This article presents three case studies, primarily based on charters, to showcase the military orders' interaction with the local bishops, focusing on the Hospitallers and the bishop of Acre, the Templars and the bishop of Tortosa, and the Teutonic Knights and the bishop of Hebron. In Acre, the bishops tried, with varying success, to monitor and curtail the activities of the Hospitallers' clergy. That tensions between the two parties increased in the course of the thirteenth century had much to do with the fact that more exempt institutions were making their home in Acre. Interaction between the bishop of Tortosa and the Templars revolved around tithes, but was also impacted by the fact that both were, in effect, co-ruling the diocese. With regard to the titular see of

* ORCID: https://orcid.org/0000-0002-4554-5288 
Hebron, the Teutonic Knights found themselves in the crosshairs of title investigations, but ultimately benefited from their interaction with the bishop who helped supply them with indulgences. In all cases, the documentation suggests recurrent conflicts, however, it also reveals a pronounced ability to compromise for the benefit of parishioners and pilgrims alike.

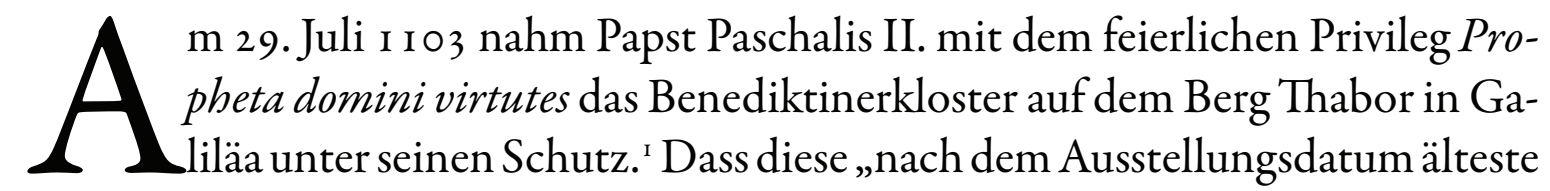
erhaltene Papsturkunde für eine geistliche Institution der Kreuzfahrerstaaten “ ${ }^{2}$ heute als Transsumpt (Insert) in einem Archiv der Johanniter liegt, ${ }^{3}$ hängt damit zusammen, dass letztere das Thaborkloster 1255 übernommen ${ }^{4}$ und dessen Urkunden als Teil ihres eigenen Archivs noch vor I29I in den Westen gerettet hatten. ${ }^{5}$ Damit sind wir beim Thema, sowohl in archivgeschichtlicher wie auch in inhaltlicher Hinsicht, denn abgesehen von dem besagten Johanniterarchiv gelten

I Papsturkunden für Kirchen im Heiligen Lande, hrsg. v. Rudolf Hiestand, Vorarbeiten zum Oriens Pontificius III, Abhandlungen der Akademie der Wissenschaften in Göttingen, Philologisch-Historische Klasse, Dritte Folge 136 (Göttingen: Vandenhoeck \& Ruprecht, 1 985 ), 92-99 Nr. 5 (Propheta domini virtutes); Regesta Regni Hierosolymitani (MXCVII-MCCXCI) mit Additamentum, hrsg. v. Reinhold Röhricht (Innsbruck: Libreria Academica Wegneriana, I 893 und 1904), Nr. 39; Revised Regesta Regni Hierosolymitani Database, zugegriffen am 2 I. März 20 I 9, http://www.crusades-regesta.com [im folgenden abgekürzt als: RRRHD], Nr. 7 I .

2 Papsturkunden für Kirchen im Heiligen Lande, hrsg. v. Hiestand, 93.

3 Valletta, National Library of Malta, Archives of the Order of Malta I, 6, 2 (Transsumpt vom 23. Juli I 255). Vgl. Papsturkunden für Kirchen im Heiligen Lande, hrsg. v. Hiestand, 70-7 I.

4 Cartulaire général de l'Ordre des Hospitaliers de S. Jean de Jérusalem (IIoo-I3IO), hrsg. v. Joseph Delaville Le Roulx, Bd. II, I200-I260 (Paris: Ernest Leroux, I 897), 777 Nr. 2726 (Favor religionis et devotionis vestre); Regesta Regni Hierosolymitani, hrsg. v. Röhricht, Nr. I230. Vgl. Jonathan Riley-Smith, The Knights of St. John in Jerusalem and Cyprus c. Io5o-I3Io (London: Macmillan/St. Martin's Press, 1967), 413-4 I 7; Martin Rheinheimer, Das Kreuzfahrerfürstentum Galiläa, Kieler Werkstücke, Reihe C: Beiträge zur europäischen Geschichte des frühen und hohen Mittelalters I (Frankfurt am Main: Peter Lang, 1990), 250; Wolfgang Antweiler, Das Bistum Tripolis im I2. und I3. Jahrhundert: Personengeschichtliche und strukturelle Proble$m e$, Studia humaniora, Düsseldorfer Studien zu Mittelalter und Renaissance 20 (Düsseldorf: Droste Verlag, I 991), I 61-i 62.

5 Dieser Thaborurkunden sind ediert in Cartulaire, hrsg. v. Delaville Le Roulx, 2: 897-914 Nr. I-XXVI. Vgl. Papsturkunden für Templer und Johanniter: Archivberichte und Texte, hrsg. v. Rudolf Hiestand, Vorarbeiten zum Oriens Pontificius I, Abhandlungen der Akademie der Wissenschaften in Göttingen, Philologisch-Historische Klasse, Dritte Folge 77 (Göttingen: Vandenhoeck \& Ruprecht, I 972), I 4; Papsturkunden für Kirchen im Heiligen Lande, hrsg. v. Hiestand, 69; Margarete Polok, "Ein Kreuzfahrerkloster unter strukturellen und prosopographischen Aspekten: Die Abtei auf dem Berge Thabor im i 2. und i 3. Jahrhundert," Staatsexamensarbeit, Heinrich-Heine-Universität Düsseldorf, I 995, 4 [Maschinenschrift]. 
beinahe alle anderen Archive der Kreuzfahrerstaaten als verloren, darunter auch das der Templer, während es für den Deutschen Orden immerhin das sogenannte Berliner Chartular und Archivreste in Venedig gibt. ${ }^{6}$ Kein einziges Bistumsarchiv hat überlebt, und das ist bedauerlich, wissen wird doch, um bei dem Kloster auf dem Thabor zu bleiben, dass Erzbischof Heinrich von Nazareth als zuständiger Diözesan gegen dessen Inkorporation in den Johanniterorden lange Widerstand leistete. ${ }^{7}$ Der Gesamteindruck ist also, wie nicht selten, überlieferungsbedingt verzerrt.

Die Forschung hat die Rolle der Ritterorden in den regionalen kirchlichen Strukturen des Mittelalters bisweilen recht kritisch bewertet, ${ }^{8}$ was im Hinblick auf das Heilige Land wohl auch auf das vernichtende Urteil des Chronisten Wilhelm von Tyrus (ca. I I 30- I I 86) zurückzuführen sein dürfte, der als Erzbischof freilich

6 Zur Archivsituation im Hinblick auf die Kreuzfahrerstaaten, sowie die dort ansässigen Ritterorden, vgl. unter anderem Papsturkunden für Templer und Johanniter: Archivberichte und Texte, hrsg. v. Hiestand, I2-38; Tabulae ordinis Theutonici ex tabulari regii Berolinesis codice potissimum, hrsg. v. Ernst Strehlke (Berlin: Weidmann, I 869 (Nachdruck mit einer Einleitung von Hans Eberhard Mayer: Toronto: University of Toronto Press, 1975)), 27-33; Rudolf Hiestand, "Zum Problem des Templerzentralarchivs," Archivalische Zeitschrift 76 ( 980 ): 17-38; Papsturkunden für Templer und Johanniter. Neue Folge, hrsg. v. Rudolf Hiestand, Vorarbeiten zum Oriens Pontificius II, Abhandlungen der Akademie der Wissenschaften in Göttingen, Philologisch-Historische Klasse, Dritte Folge I 35 (Göttingen: Vandenhoeck \& Ruprecht, 1984), 19; Papsturkunden für Kirchen im Heiligen Lande, hrsg. v. Hiestand, 19-86, hier vor allem 6o; Anthony Luttrell, "The Hospitallers' Early Written Records," in The Crusades and Their Sources: Essays Presented to Bernard Hamilton, hrsg. v. John France und William G. Zajac (Aldershot: Ashgate, I 998), I 35-1 54; Hans Eberhard Mayer, Die Kanzlei der lateinischen Könige von Jerusalem, Bd. I-II, Monumenta Germaniae Historica, Schriften 40 (Hannover: Hahnsche Buchhandlung, 1996), I: 4; Anthony Luttrell, "The Hospitallers' Early Statutes," Revue Mabillon I 4 (2003): 9-22; Jochen Burgtorf, The Central Convent of Hospitallers and Templars: History, Organization, and Personnel (I099/II20-I3IO), History of Warfare 50 (Leiden-Boston: Brill, 2008), 4-I 2; Jonathan Riley-Smith, Templars and Hospitallers as Professed Religious in the Holy Land, The Conway Lectures in Medieval Studies 2008 (Notre Dame: University of Notre Dame Press, 20 Io), 73 (Anm. I 5 ).

7 Polok, "Ein Kreuzfahrerkloster," I 9. Vgl. Bernard Hamilton, The Latin Church in the Crusader States: The Secular Church (London: Variorum Publications Ltd., I 980 ), I 1 I, 293-295.

8 Vgl. Hans Prutz, Die Geistlichen Ritterorden: Ibre Stellung zur kirchlichen, politischen, gesellschaftlichen und wirtschaftlichen Entwicklung des Mittelalters (Berlin: Ernst Siegfried Mittler und Sohn, I908 (Nachdruck: Berlin: Haude \& Spenersche Verlagsbuchhandlung, I 977)), I 42-1 94; Hamilton, The Latin Church, I09; Helen Nicholson, Templars, Hospitallers and Teutonic Knights: Images of the Military Orders, II28-I29I (Leicester: Leicester University Press, I993), 4I-43. Zu einer differenzierten Einschätzung des Verhältnisses zwischen den Ritterorden und den Diözesanbischöfen, vor allem in Süditalien/Sizilien und Portugal, gelangt Kristjan Toomaspoeg, "The Military Orders and the Diocesan Bishops: A Pragmatic Relationship," Ordines Militares Colloquia Torunensia Historica. Yearbook for the Study of the Military Orders 23 (2018): 93-I 25. 
selbst dem Weltklerus angehörte und deswegen alles andere als unparteiisch war. ${ }^{9}$ Dazu seien hier nur zwei Beispiele aus der deutschen Geschichtswissenschaft genannt, ein älteres und ein neueres. In seiner 1908 veröffentlichten vergleichenden Studie zu den Ritterorden schrieb Hans Prutz ( I 843-1929), man könne sich angesichts der Tatsache, dass deren

„eximierte Stellung [...] die kirchlichen, finanziellen und zum Teil auch weltlichen Rechte [...] [der Bischöfe] kürzte, ihnen ganze Gemeinden entzog und eine Menge von Kirchen [...] aus dem Diözesanverband löste, [...] eine Vorstellung machen von den Wirkungen, welche diese Verhältnisse auf die Kirche überhaupt ausüben musste: sie kann nur eine zersetzende gewesen sein." ${ }^{\text {"10 }}$

Und 2015 gab Thomas Krämer seiner Untersuchung zu den Konflikte[ $n]$ und ibre $[r]$ Beilegung im Umfeld der geistlichen Ritterorden den programmatischen Haupttitel Dämonen, Prälaten und gottlose Menschen, ${ }^{11}$ und zwar durchaus in Anlehung an den verbalen und visuellen Diskurs der Zeit. ${ }^{12}$ Der vorliegende Beitrag möchte sich den Ritterorden in den regionalen kirchlichen Strukturen der Kreuzfahrerstaaten anhand von drei Fallstudien nähern, welche die Johanniter mit dem Bischof von Akkon, die Templer mit dem Bischof von Tortosa und den Deutschen Orden mit dem Bischof von Hebron in Verbindung bringen. Dabei geht es nicht etwa um die Vergleichbarkeit dieser drei Szenarien, sondern vielmehr um deren repräsentative Vielfalt.

9 Vgl. Peter W. Edbury und John Gordon Rowe, William of Tyre: Historian of the Latin East, Cambridge Studies in Medieval Life and Thought, 4. Serie (Cambridge: Cambridge University Press, I 988), I 23-I 29; Nicholson, Templars, 45-46.

10 Prutz, Die Geistlichen Ritterorden, 529.

1 Thomas Krämer, Dämonen, Prälaten und gottlose Menschen: Konflikte und ibre Beilegung im Umfeld der geistlichen Ritterorden, Vita regularis, Ordnungen und Deutungen religiosen Lebens im Mittelalter, Abhandlungen 64 (Berlin: Lit Verlag, 2015).

12 Ebd., 3-5. Zum verbalen Diskurs, vgl. Nicholson, Templars, 35-56; zum visuellen Diskurs, vgl. beispielsweise die Studie zu den neuentdeckten Fresken in der Johanniterkapelle auf der Burg Margat im Fürstentum Antiochia, Balázs Major und Éva Galambos, "Archaeological and Fresco Research in the Castle Chapel at al-Marqab: A Preliminary Report on the Results of the First Seasons," in The Military Orders, Bd. 5, Politics and Power, hrsg. v. Peter W. Edbury (Farnham: Ashgate, 20 I 2), 23-47, hier 30-35. 


\section{Die Johanniter Und Der Bischof Von AkKon}

Begeben wir uns also zunächst zu den Johannitern nach Akkon. Erobert i I 04 durch König Balduin I. von Jerusalem, kam diese Küstenstadt zur Krondomäne. ${ }^{13}$ Bei ihrer Hauptkirche, der Heiligkreuzkathedrale, handelte es sich zunächst um eine umgewandelte Moschee, aber einen lateinischen Bischof finden wir dort erst nach I I 30 , was wohl damit zusammenhängt, dass Tyrus, der zuständige Metropolitansitz im Patriarchat Jerusalem, selbst erst I I 24 von den Kreuzfahrern erobert wurde. ${ }^{14}$ Dagegen verfolgten die Johanniter offenbar bereits mindestens zwanzig Jahre vor dem Erscheinen dieses Bischofs eigene Interessen in Akkon, zumal ihnen Balduin I. bereits I I 10 ihren Besitz in dieser Stadt bestätigt hatte. ${ }^{15}$ Dies ist zwar ordensgeschichtlich ungewöhnlich, aber gerade deswegen auch interessant.

Die erste erhaltene Bischofsurkunde für die Johanniter in Akkon stammt aus dem Jahr I 135 und liegt im Original vor. ${ }^{16}$ Ihr Aussteller, ein gewisser Johannes,

13 Zu Akkon, vgl. unter anderem Giorgio Fedalto, La Chiesa Latina in Oriente, Bd. I, Studi religiosi 3 (Verona: Casa Editrice Mazziana, I 98 I , 2. Auflage), I 5 6- I 57; ders., La Chiesa Latina in Oriente, Bd. II, Hierarchia Latina Orientis, Studi religiosi 3 (Verona: Casa Editrice Mazziana, 1 976), 26-28; Papsturkunden für Kirchen im Heiligen Lande, hrsg. v. Hiestand, 58-6 ; Denys Pringle, Secular Buildings in the Crusader Kingdom of Jerusalem: An Archaeological Gazetteer (Cambridge: Cambridge University Press, I 997), I 5-17; David Jacoby, "Acre," in The Crusades: An Encyclopedia, Bd. I, hrsg. v. Alan V. Murray (Santa Barbara: ABC Clio, 2006), 9-I 2; Burgtorf, The Central Convent, 83-94; Ruthy Gertwagen, "Acre," in Prier et combattre: Dictionnaire européen des ordres militaires au Moyen Agge, hrsg. v. Nicole Bériou und Philippe Josserand (Paris: Librairie Arthème Fayard, 2009), 48-50; Denys Pringle, The Churches of the Crusader Kingdom of Jerusalem: A Corpus, Bd. IV, The Cities of Acre and Tyre (with Addenda and Corrigenda to Volumes I-III) (Cambridge: Cambridge University Press, 2009), 35-40; ders., "The Military Orders in the Cities of the Holy Land," in Les Ordres militaires dans la ville médiévale, hrsg. v. Damien Carraz, Actes du colloque international de Clermont-Ferrand, 26-28 mai 20 ro, Collection Histoires croisées (Clermont-Ferrand: Presses Universitaires Blaise-Pascal, 2013), 79-95, hier 82-86.

14 Fedalto, La Chiesa, 2: 27; Pringle, The Churches, 4: 35.

is Die Urkunden der lateinischen Könige von Jerusalem, hrsg. v. Hans Eberhard Mayer, Bd. I-IV, altfranzösische Texte erstellt von Jean Richard, Monumenta Germaniae Historica, Diplomata Regum Latinorum Hierosolymitanorum (Hannover: Hahnsche Buchhandlung, 2010), 165- I68 Nr. 42; Regesta Regni Hierosolymitani, hrsg. v. Röhricht, Nr. 57; RRRHD, Nr. I I 4.

16 Valletta, National Library of Malta, Archives of the Order of Malta I, I, 29; Cartulaire général de l'Ordre des Hospitaliers de S. Jean de Jérusalem (IIO0-I3IO), hrsg. v. Joseph Delaville Le Roulx, Bd. I, II00-I200 (Paris: Ernest Leroux, I 894), 94-95 Nr. I I 2 (alle nachfolgenden Zitate aus dieser Urkunde von I 35 stammen aus dieser Edition); Codice diplomatico del sacro militare ordine Gerosolimitano oggi di Malta, hrsg. v. Sebastiano Pauli (Lucca: Salvatore e Giandomenico Marescandoli, I 733), Abbildungstafel I (nicht paginiert), Nr. I I (Siegel des Bischofs von Akkon); Regesta Regni Hierosolymitani, hrsg. v. Röhricht, Nr. I 55; RRRHD, Nr. 332 . Zu Bischof Johannes von Akkon, vgl. Fedalto, La Chiesa, 2: 27. 
erscheint mit der Selbstbezeichnung „erster Bischof der Lateiner der Stadt Akkon“ (primus latinorum tholomaide civitatis episcopus) und gab an, er handle „zur Vergebung der Sünden, die er und die Seinen unwissend gegenüber Gott begangen hätten" (in peccatorum nostrorum remissionem que ignoranter contra deum deliquimus), und wie wir sehen werden handelte es sich dabei um mehr als nur eine Floskel. Bischof Johannes schenkte den Johannitern für die Bedürfnisse der Armen auf Dauer den gesamten Zehnten aller Einkünfte, die sie in seinem Bistum einsammelten und ihm schuldeten. Es folgt die Siegelankündigung, und man denkt eigentlich, das Stück sei schon zuende, doch dann geht es überraschend weiter. Ausserdem, so heisst es, verzichteten die Johanniter gegenüber dem Bischof auf „eine gewisse Klage, die sie lange aufrechterhalten hatten“ (querelam quamdam, quam erga nos diu habuerunt), und zwar "hinsichtlich des Nordportals der Heiligkreuzkathedrale, das an der Stelle eines vormaligen Johanniterhauses errichtet worden war" (propter portam superiorem ecclesie sancte crucis ab aquilone fundatam que in loco cuiusdam domus fratrum hospitalis edificata fuit).

Bei den „unwissend“ begangenen Sünden des Bischofs handelte es sich also höchstwahrscheinlich um Bauen ohne Baugenehmigung, beziehungsweise um unrechtmässige Besitzentfremdung, und zwar scheinbar nicht bloss im Rahmen eines kleineren Anbaus an die umfunktionierte Moschee, sondern vielmehr im Rahmen eines neuen Kirchenbaus. ${ }^{17}$ Schon aus Personalgründen konnten die Johanniter in ihrer Frühzeit die an sie gemachten Schenkungen sicher nicht immer genau beobachten, zudem mögen den Einwohnern der Stadt die genauen Besitzverhältnisse im Umfeld der ehemaligen Moschee unbekannt gewesen sein, und dem neuen Bischof möchte man wohl kaum Böswilligkeit unterstellen. Letzterer konnte freilich nicht ahnen, dass Papst Innozenz II. den Johannitern nur anderthalb Monate später das feierliche Privileg $A d$ hoc nos verleihen würde. ${ }^{18}$ Dies stellte die Johanniter (abermals) unter den apostolischen Schutz und bestätigte ihre Besitzungen einschliesslich des Zehnten, vor allem aber befreite es die Johanniter „von der kirchlichen Strafgewalt“, und damit begann, so Rudolf Hiestand, „die Geschichte des Hospitals als einer exemten Institution der Kirche. Zur finanziellen, von den Bischöfen selbst zugestandenen Freiheit war jetzt die vom Papsttum verliehene jurisdiktionelle Freiheit getreten. ${ }^{\text {"19 }}$ Und die Nachfolger von Bischof

Vgl. dazu Pringle, The Churches, 4: 36.

I8 Cartulaire, hrsg. v. Delaville Le Roulx, I: 95-96 Nr. I I 3 ; Papsturkunden für Templer und Johanniter. Neue Folge, hrsg. v. Hiestand, 206-207 Nr. 4.

19 Rudolf Hiestand, "Die Anfänge der Johanniter," in Die geistlichen Ritterorden Europas, hrsg. v. Josef Fleckenstein und Manfred Hellmann, Vorträge und Forschungen XXVI (Sigmaringen: Jan Thorbecke Verlag, I 980), 3 I-80, hier 59. Vgl. auch Klaus-Peter Kirstein, Die lateinischen Patriarchen von Jerusalem: Von der Eroberung der Heiligen Stadt durch die Kreuzfahrer Iogg bis 
Johannes hatten es bei den Johannitern eben nicht länger mit abwesenden oder unwissenden Immobilienbesitzern zu tun, sondern mit Mitgliedern einer zunehmend selbstbewussten internationalen Gemeinschaft, deren ursprünglich karitative und spirituelle Aufgaben in zunehmendem Masse durch militärische und administrative Verpflichtungen erweitert wurden.

Den vielleicht schönsten, sicher aber umfassendsten Einblick in das Agieren der Johanniter in den kirchlichen Strukturen von Akkon gewährt uns eine Urkunde von I 175, die im Manosquer Inventar von I 53 I ganz unschuldig regestiert wird als „eine Übereinkunft hinsichtlich aller zwischen der Akkoner Kirche und dem Jerusalemer Johanneshospital bestehenden Fragen" (ung acord faict de toutes questions, qui estoient entre la eglise de Accon et l'Ospital de Sainct Jehan de Jherusalem).${ }^{20}$ Der urprüngliche Text dieses ebenfalls im Original erhaltenen Stükkes wird da schon deutlicher. ${ }^{21}$ Es sei ein „Friede und eine Einigung hinsichlich aller Klagen, die es seit langem zwischen den beiden Parteien gegeben habe" (pax et concordia omnium querimoniarum que diu habite sunt inter acconensem ecclesiam et domum hospitalis). ${ }^{22}$ Bischof Joscius von Akkon und der Johannitermeister Josbert einigten sich in insgesamt zehn Punkten.

Erstens solle der Bischof auf Bitten des Johanniterpriors jene Johanniter, die Briefe von ihren jeweiligen Bischöfen, also den Prälaten ihres Herkunftsortes, hätten, oder die sich durch ihre Lebensführung auszeichneten, zu Klerikern und Vikaren weihen. Knaben, die bei den Johannitern aufgezogen worden und von legitimer Geburt seien (pueris vero in eadem nutritis et legitime natis), solle er bis zum Subdiakon weihen. Zweitens solle der Bischof den Johannitern am Karsamstag das Krankenöl (oleum infirmorum) zur Salbung jener Brüder und Mitbrüder geben, die ihre gesamte Habe den Johannitern vermacht hätten, sowie zur Salbung jener, die zum Tisch des Hauses (propria mensa domus hospitalis), also zur Hausgemeinschaft der Johanniter, gehörten. Ohne Genehmigung des Bischofs dürften die Johanniter nur jene Pilger salben, die bei ihnen wohnten. Drittens solle der Priester jene Pfarreiangehörigen, die auf dem Johanniterfriedhof (in cimiterio hospitalis) beigesetzt werden wollten, daran erinnern, dass sie dazu die Erlaubnis des Bischofs

zum Ende der Kreuzfahrerstaaten I29I, Berliner Historische Studien 35, Ordensstudien XVI (Berlin: Duncker \& Humblot, 2002), 248-25 I.

20 Marseilles, Archives départementales (Bouches-du-Rhône), Ordre de Malte 56 H 68 (Inventaire de Manosque a. I 53 I), fol. 705 (94 Z).

${ }_{21}$ Valletta, National Library of Malta, Archives of the Order of Malta I, 3, 25; Cartulaire, hrsg. v. Delaville Le Roulx, I: 323-324 Nr. 47 I; Regesta Regni Hierosolymitani, hrsg. v. Röhricht, Nr. 532; RRRHD, Nr. 947.

22 Cartulaire, hrsg. v. Delaville Le Roulx, I: 323-324 Nr. 47 I (alle nachfolgenden Zitate aus dieser Urkunde von i 75 stammen aus dieser Edition). 
bräuchten, damit ihr Testament rechtskräftig bleibe. Der Bischof oder sein Vikar sollten dem stattgeben, solange die Pfarreirechte gewahrt blieben. Viertens sollten sowohl die Kapläne der Heiligkreuzkathedrale als auch die der Johanniter, wenn sie Kranke besuchten, seien es Bürger oder Pilger, diese zu Spenden an die jeweils andere Institution ermuntern und sich darüber gegenseitig unterrichten, letzteres wohl um eine entsprechende schriftliche Festlegung zu gewährleisten. Fünftens solle der Bischof den Knaben, die bei den Johannitern unterrichtet werden wollten (in domo hospitalis doceri cupientes), dies nicht verbieten: ein seltener Hinweis auf eine Johanniterkommende als Erziehungsanstalt.

Sechstens sollten sich pfarreiangehörige Mütter, die entbunden hätten, dort der Reinigung unterziehen, wo ihre Kinder getauft worden seien, also in der Heiligkreuzkathedrale. In der Johanniterkirche sollten sie ohne bischöfliche Erlaubnis (sine episcopi licentia) keine Aufnahme finden. Die besagte Reinigung (purificatio), so sei hier ergänzt, war nach biblischem Vorbild eine kirchliche Einnahmequelle (Leviticus I 2; Lucas 2:22-24). Siebtens, wenn ein Pfarreiangehöriger zur Fastenzeit (quadragesimali tempore) gegenüber einem Johanniterkaplan die Beichte ablegen wollte, so solle dieser ihn ermahnen, dass er nach Pfarreirecht, bevor er die Heilige Kommunion empfangen könne, die Beichte gegenüber dem Kaplan seiner eigenen Pfarrei ablegen müsse. Sollte er dies nicht wollen, so solle ihm die Beichte trotzdem abgenommen und eine Busse auferlegt werden. Achtens, wenn sich Leichenzüge der jeweiligen Vertragsparteien begegneten, so solle der zuerst kommende Leichenzug dem nachfolgenden Leichenzug die übriggebliebenen Kerzen (cereos impositos candelabris) belassen. Neuntens, wenn ein Kranker, der sein Testament zu Händen eines Akkoner Kaplans gemacht habe, zu den Johannitern gebracht werden wolle und dort innerhalb von sieben Tagen stürbe, so solle sein Testament gültig bleiben, wenn auch einschliesslich etwaiger Änderungen. Zehntens, wenn der Bischof oder der Johanniterprior eine Predigt hielten, so sollten sie das Volk zu Spenden an die jeweils andere Institution ermuntern.

Dieser letzte Punkt erinnert uns an die Behauptung in der Chronik Wilhelms von Tyrus, die Johanniter in Jerusalem würden aus lauter Boshaftigkeit immer dann ihre Glocken läuten (pulsatis campanis), wenn der Patriarch predigen wolle. ${ }^{23}$ In Akkon hätten sie sich mit einer solchen Aktion demnach selbst geschadet. Hans Eberhard Mayer zufolge war der Einigungsvertrag von i 75 ein „Erfolg“ für den Bischof, „denn die Ordensrechte in der Stadt wurden deutlich limitiert.“ ${ }^{24}$

23 Guillaume de Tyr, Chronique, hrsg. v. Robert B. C. Huygens, Identifizierung der historischen Quellen und Datierungen von Hans Eberhard Mayer und Gerhard Rösch, Corpus Christianorum, Continuatio Mediaevalis, LXIII-LXIII A (Turnhout: Brepols, I 986), 8 I 3 (XVIII, 3 ). Vgl. Hamilton, The Latin Church, 74.

24 Mayer, Die Kanzlei, I: 280. 
Ausserdem zeigt dieser Einigungsvertrag, so schon Jonathan Riley-Smith, wie kompliziert es auf der Pfarreiebene wurde, wenn die Johanniter aufgrund ihrer Privilegien das Recht hatten, eigene Kapläne zu haben, Tote zu beerdigen und Schenkungen entgegenzunehmen, und da Akkon eine wichtige Durchgangsstation des Pilgerverkehrs mit einem grossen Hospital war, wurde die Situation in der Folgezeit, so meint Riley-Smith, eher noch angespannter. ${ }^{25}$ I 799 nahm Bischof Joscius von Akkon zusammen mit anderen Vertretern des lateinischen Klerus aus den Kreuzfahrerstaaten am Dritten Laterankonzil teil ${ }^{26}$ welches mit seinem 9. Kanon die Templer und Johanniter und ihre Verletzung von Diözesanrechten ins Visier nahm. ${ }^{27} \mathrm{Ob}$ Joscius unterdessen neuen Grund zur Klage hatte, ist freilich nicht bekannt. Doch darf all dies nicht den Blick darauf verstellen, dass sich der Bischof und die Johanniter in Akkon eben einigen konnten, was letztlich beiden Parteien, vor allem aber den Bürgern und auch den Pilgern, zugute kam.

Nach vorübergehender Besetzung durch die Muslime von I I 87 bis I I 9 I wurde Akkon durch den Dritten Kreuzzug zurückerobert. Im April I 200 kam es dann zu einem neuen Vergleich, diesmal zwischen Bischof Theobald von Akkon und dem Johannitermeister Gottfried von Donjon..$^{28}$ Darin übertrug Theobald den Johannitern formell ihren Friedhof und erlaubte dessen Ummauerung (ad claudendum), sowie den Bau einer Friedhofskapelle (ad capellam in eodem cimiterio construendam), in welcher die Johanniter, wann immer sie wollten, Gottesdienst feiern durften. Ausserdem sagte er zu, und damit erreichen wir in Akkon eine neue Entwicklungsstufe, er werde ihnen im Hinblick auf jene, die sich gewaltsam an ihnen oder ihrem Besitz in seiner Diözese vergreifen sollten, volles Recht verschaffen, und zwar im Einklang mit den ihnen bereits verliehenen päpstlichen Privile-

25 Riley-Smith, The Knights, 406.

26 Sacrorum conciliorum nova et amplissima collectio, hrsg. v. Giovanni Domenico Mansi, Bd. XXII (Venedig: Apud Antonium Zatta, 1778), col. 2 1 5; Spicilegium sive Collectio veterum aliquot scriptorum: Nova Editio, hrsg. v. Luc d'Achéry, Étienne Baluze, Edmond Martène und Louis François Joseph de la Barre, Bd. I (Paris: Apud Montalant, 1723), 637; Guillaume de Tyr, Chronique, hrsg. v. Huygens, 996 (XXI, 25 (26)); Regesta Regni Hierosolymitani, hrsg. v. Röhricht, Nr. 575; RRRHD, Nr. 1023.

27 Conciliorum Oecumenicorum Decreta, hrsg. v. Giuseppe Alberigo, Periclis-Petros Ioannou, Claudio Leonardi und Hubert Jedin (Basel-Barcelona-Freiburg-Rom-Wien: Herder, 1 962 ), I 9 I-I 93, hier I 92: Fratrum autem et coepiscoporum nostrorum vehementi conquestione comperimus, quod fratres Templi et Hospitalis, alii quoque religiosae professionis, indulta sibi ab apostolica sede excedentes privilegia, contra episcopalem auctoritatem multa praesumunt, quae et scandalum generant in populo Dei et grave pariunt periculum animarum. Vgl. Kirstein, Die lateinischen Patriarchen, 333.

28 Cartulaire, hrsg. v. Delaville Le Roulx, I: 689-690 Nr. I I 3 (alle nachfolgenden Zitate aus dieser Urkunde von 1200 stammen aus dieser Edition); Regesta Regni Hierosolymitani, hrsg. v. Röhricht, Nr. 77 I; RRRHD, Nr. I 469. 
gien (juxta privilegia eisdem fratribus ab apostolica sede indulta), sowie dann, wenn ihn Mandate des Papstes (a summo pontifice mandata) dazu anhalten sollten.

Die Forderung der Kurie an die Bischöfe, die Johanniter und ihren Besitz vor Übergriffen zu schützen, findet sich schon sehr früh, beispielsweise in einer Legatenurkunde aus der Zeit Paschalis' II. ${ }^{29}$ und in einem Mandat Alexanders III. von I I 63..$^{\circ 0}$ Allerdings konnte Theobald sein Schutzversprechen leider nicht mehr selbst umsetzen, denn einem Brief des Johannitermeisters an den englischen Prior seines Ordens aus dem folgenden Jahr ( I 20I) ist zu entnehmen, dass der Bischof von Akkon, hier an erster Stelle genannt, sowie etliche Johanniterbrüder und Pilger, auf dem Weg in den Westen ,in Angelegenheiten des Heiligen Landes“ (pro negotio Terrae Sanctae) bei einem Schiffbruch im Mittelmeer unweit der tripolitanischen Küste umgekommen waren. ${ }^{31}$ Unter Theobalds Nachfolgern spannte sich das Verhältnis zwischen den Johannitern und den Bischöfen von Akkon immer wieder an, was aber auch damit zu tun hatte, dass es in Akkon „eng“ wurde, und zwar nicht so sehr wegen der Zahl der dort befindlichen annähernd sechzig Kirchen und Kapellen, sondern wegen der steigenden Zahl jener Einrichtungen, die vom Zugriff des Bischofs von Akkon exemt waren..$^{32}$ Als Jakob von Vitry i 2 i 6 als neuer Bischof in Akkon eintraf, schrieb er an seine Freunde in Paris: „Ich habe festgestellt, dass Akkon wie ein Monster ist, eine Bestie mit neun Häuptern, die alle miteinander streiten. ${ }^{33}$ Dass bei einigen Streitigkeiten zwischen den Bischöfen von Akkon und den Johannitern im I 3. Jahrhundert päpstliche Legaten oder delegierte Richter beigezogen werden mussten, ${ }^{34}$ suggeriert vielleicht einen

29 Ausgestellt ( I I 02 - I I I 5) durch Richard, den Kardinalbischof von Albano und päpstlichen Legaten Paschalis' II., und adressiert an die Bischöfe auf der Iberischen Halbinsel (Novit fratres discretio vestra): Cartulaire, hrsg. v. Delaville Le Roulx, I: I 2-I 3 Nr. 8.

30 Ausgestellt am 4. Juni ( I I 63), aber möglicherweise auch schon früher, durch Papst Alexander III. und adressiert an den gesamten Klerus (Quanto maior ab universis Dei fidelibus): Cartulaire, hrsg. v. Delaville Le Roulx, I: 229 Nr. 3 I 9.

${ }_{31}$ Cartulaire, hrsg. v. Delaville Le Roulx, 2: I -2 Nr. I I 3 I: navi confracta in maritima Tripolis ante Biblium, Aconensis episcopus, et plures viri honestissimi fratrum nostrorum, ad vos pro negotio Terre Sancte destinati, cum multis, tam nobilibus quam humilibus peregrinis, ad dolorem et gemitum totius populi Christiani, sicut Domino placuit, sub aquis vehementibus perierunt; Regesta Regni Hierosolymitani, hrsg. v. Röhricht, Nr. 787; RRRHD, Nr. 1489.

32 Hamilton, The Latin Church, 299-30 I.

33 Lettres de Jacques de Vitry (II60/II70-I240), évêque de Saint-Jean-d'Acre, hrsg. v. Robert B. C. Huygens (Leiden: Brill, I 960), 79-97 Nr. 2, hier 83 (Zeilen I I 2- I I 3): inveni autem civitatem Acconensem tanquam monstrum et beluam IX capita sibi adinvicem repugnantia habentem. Vgl. Hamilton, The Latin Church, 299.

$34 \mathrm{Zu}$ den Beziehungen zwischen den Bischöfen von Akkon und den Johannitern, vgl. Riley-Smith, The Knights, 406-410; ders., The Knights Hospitaller in the Levant, c. 1070-1309 (Basingstoke-New York: Palgrave Macmillan, 20 I 2), 78, I 67-1 70, 283. 
gewissen Rückgang der Kompromissbereitschaft, mag aber auch mit der Überlieferungslage zusammenhängen, denn immer dann, wenn man sich versteht und routinemässig im beiderseitigen Einvernehmen handelt, stellt man darüber eben keine Urkunden aus.

\section{Die Templer und DeR Bischof Von ToRTOSA}

Wenden wir uns nun den Templern in Tortosa zu. Gelegen an der syrischen Küste auf halbem Weg zwischen Tripolis im Süden und Valenia im Norden, wurde diese alte Bischofsstadt bereits durch den Ersten Kreuzzug erobert, ging aber kurzzeitig wieder verloren und musste I 102 erneut erobert werden. ${ }^{35}$ Tortosa galt als eines der ältesten Marienheiligtümer und wurde deswegen auch von der muslimischen Bevölkerung der Stadt und des Umlands besucht. ${ }^{36}$ Für das von den Pilgern hochverehrte Marienbild mit dem Jesuskind, angeblich eine vom Heiligen Lukas selbst angefertigte Ikone, wurde im I 2. Jahrhundert eine Kathedrale errichtet, die bis in die Neuzeit überdauert hat. ${ }^{37}$ Einen lateinischen Bischof gab es in Tortosa seit ungefähr I I $27.3^{38}$ Herrschaftsrechtlich ein Teil der Grafschaft Tripolis, gehörte Tortosa kirchenrechtlich zum Erzbistum Tyrus. Da Tyrus jedoch ein Zankapfel zwischen den Patriarchaten von Jerusalem und Antiochia war, und Tortosa zudem relativ nahe an der Grenze zum Fürstentum Antiochia lag, hatte

$35 \mathrm{Zu}$ Tortosa, vgl. unter anderem Paul Deschamps, La défense du comté de Tripoli et de la principauté d'Antioche: Étude historique, géographique, toponymique et monumentale, Texte, Les châteaux des Croisés en Terre Sainte 3, Institut Français d'Archéologie de Beyrouth, Bibliothèque Archéologique et Historique 90 (Paris: Librairie Orientaliste Paul Geuthner, 1973), 287-292; Fedalto, La Chiesa, I: I I 5, I 53; Fedalto, La Chiesa, 2: 39-40; Papsturkunden für Kirchen im Heiligen Lande, hrsg. v. Hiestand, 78; Alan Forey, The Military Orders: From the Twelfth to the Early Fourteenth Centuries, New Studies in Medieval History (Basingstoke-London: Macmillan, 1992), 60-62; Hugh Kennedy, Crusader Castles (Cambridge: Cambridge University Press, 1994), I 32-1 38; Peter Thorau, "Tortosa," in Lexikon des Mittelalters, Bd. VIII, Stadt (Byzantinisches Reich) bis Werl (Stuttgart-Weimar: Verlag J. B. Metzler, 1999; Erstveröffentlichung: 1996-1997), 884-885; Hugh Kennedy, "Tortosa (Syria)," in The Crusades, hrsg. v. Murray, 4: I I 86; Pierre-Vincent Claverie, “Tortose," in Prier et combattre, hrsg. v. Bériou und Josserand, 92 I; Balázs Major, Medieval Rural Settlements in the Syrian Coastal Region (I 2th and I3th Centuries), Archaeolingua: Central European Archaeological Heritage Series 9 (Oxford: Archaeopress Archaeology, 2015 ), 44.

36 Vgl. Kevin James Lewis, The Counts of Tripoli and Lebanon in the Twelfth Century: Sons of Saint-Gilles, Rulers of the Latin East (London-New York: Routledge, 20 I 7), I 6, 36, 216.

37 Vgl. Hamilton, The Latin Church, ı 8, 28 5-286; Thorau, "Tortosa," 885 ; Jaroslav Folda, Crusader Art in the Holy Land, from the Third Crusade to the Fall of Acre, II87-I29I (Cambridge: Cambridge University Press, 2005), 8 I -83, vor allem 8 I.

38 Fedalto, La Chiesa, 2: 40; Papsturkunden für Kirchen im Heiligen Lande, hrsg. v. Hiestand, 78. 
der antiochenische Patriarch dort erheblich mehr Gewicht. ${ }^{39}$ Vielleicht war dieser rechtsunsichere Raum im Grenzgebiet der nordsyrischen Kreuzfahrerstaaten für die Ritterorden eben gerade auch deswegen besonders attraktiv, weil man sich dort ungestörter entfalten konnte. ${ }^{4}$

Als Einstieg dient uns hier eine von Alan Forey im Nationalarchiv Madrid entdeckte und von Jonathan Riley-Smith edierte Urkunde aus dem Jahr I I 52 (bestätigt I 57 und überliefert in einer wohl für die Johanniter angefertigten Abschrift von 1 377). In ihrem Text geht es um „einen Frieden und eine Eintracht“ (pax et concordia) zwischen Bischof Wilhelm von Tortosa und dem Templermeister Eberhard von Barres. ${ }^{41}$ Die Muslime, so die Urkunde, hätten Tortosa eingenommen und zerstört, woraufhin die Stadt verlassen dagelegen habe, „mit niedergeworfenen Altären und, oh Schmerz, durch sündhafte Entweihungen verunreingten heiligen Stätten" (altaribus prostratis loca sancta iniquis prophanacionibus, prob dolor, [...] contaminata), eine Anspielung auf den gerade erst erfolgten Überfall durch Nur ad-Din, den Herrscher von Aleppo. ${ }^{42}$ Daraufhin hatte der Bischof, nach Rücksprache mit seinem Kapitel, dem Grafen Raimund II. von Tripolis, den Baronen, Bürgern und anderen Gottesfürchtigen, die Templer gebeten, in der Stadt eine neue Burg zu errichten, damit „die Kirche der Heiligen Gottesmutter und immerwährenden Jungfrau Maria" (aecclesia sancte dei genetricis semperque virginis marie) sicher wiedererstehen könne. Die Templer hatten zugestimmt und erhielten nun, um den Bau der neuen Burg zu unterstützen, vom Bischof einen genau bezeichneten Teil der Stadt, sowie Gebiet ringsum aus einer Schenkung des Grafen.

39 Vgl. Papsturkunden für Kirchen im Heiligen Lande, hrsg. v. Hiestand, 78; Antweiler, Das Bistum, 257.

40 Jochen Burgtorf, "Die Herrschaft der Johanniter in Margat im Heiligen Land," in Die Ritterorden als Träger der Herrschaft: Territorien, Grundbesitz und Kirche, hrsg. v. Roman Czaja und Jürgen Sarnowsky, Ordines Militares. Colloquia Torunensia Historica XIV (Toruń: Wydawnictwo Uniwersytetu Mikołaja Kopernika, 2007), 27-57, hier 46-47; ders., "The Hospitaller Lordship of Margat," in East and West in the Medieval Eastern Mediterranean II: Antioch from the Byzantine Reconquest until the End of the Crusader Principality, Acta of the congress held at Hernen Castle (the Netherlands) in May 2006, hrsg. v. Krijnie Ciggaar und Victoria van Aalst, Orientalia Lovaniensia Analecta 199 (Leuven: Peeters Press, 2013 ), I I - 50, hier 42.

${ }^{41}$ Jonathan Riley-Smith, "The Templars and the Castle of Tortosa in Syria: An Unknown Document Concerning the Acquisition of the Fortress," The English Historical Review 84, no. 33 I ( 1969 ): 278-288, hier 284-287 (alle nachfolgenden Zitate aus dieser Urkunde von I I 52 stammen aus dieser Edition); RRRHD, Nr. 532. Zu Alan Foreys Entdeckung, vgl. Riley-Smith, "The Templars,” 278 (Anm. I). Ebd., 284, macht die folgenden archivalischen Angaben: „(Ms. Archivo Nacional, Madrid. Ordenes Militares. Montesa: documentos particulares I, No. 2. Copy made in $\mathrm{I} 377$ ).“

42 Malcolm Barber, The Crusader States (New Haven-London: Yale University Press, 20 I 2 ), I 98. 
Alle Kirchen in der Stadt Tortosa und ihrem Hafenbereich, abgesehen von der Kapelle der Templerbrüder in der Burg von Tortosa, sollten „pfarreirechtlich“ (cum parochia) der Kirche und dem Bischof unterstehen. Dem Orden sollten dagegen pfarreirechtlich alle weiteren Templerburgkapellen, sowie „alle weiteren Kirchen im Bistum Tortosa" (omnes alie aecclesie tocius episcopatus), unterstehen, ausgenommen sieben genannte Orte, darunter der Krak des Chevaliers, ${ }^{43}$ der den Johannitern gehörte. Falls darüberhinaus irgendetwas unter „die Herrschaft der Templer" (in eorum dominium) gelangen sollte, so sollte es ihnen pfarreirechtlich gehören. Alle Zehnteinkünfte des Bistums (omnes decime tocius episcopatus), einschliesslich der Zehnteinkünfte von Bauern und Rittern (und zwar sowohl von denen der Templer als auch von denen des Bischofs), sollten zwischen dem Bischof und den Templern geteilt werden (Istorum omnium una medietas erit aecclesie et episcopi. Altera vero medietas erit magistri fratrumque suorum). Ausgenommen von dieser Regelung waren die Eigenerträge des Bischofs und der Kanoniker, die Eigenerträge der Templer (decima proprius laboris), die Beuteerträge der Templer (illis lucris que in expedicionibus facient), die Geringeinkünfte der Templer von ihren Tieren und Gärten, die Erträge des Krak des Chevaliers, für die es bereits eine Einigung mit den Johannitern gab, die Erträge der Templer zu Chastel Blanc und die Erträge des Bischofs zu Maraclea. Beide Vertragsparteien verpflichteten sich zur Einhaltung, allerdings „vorbehaltlich der Rechte des Papstes und des Patriarchen von Antiochia“ (excepto domino papa et patriarcha antiocheno) im Hinblick auf den Bischof und seine Kanoniker, beziehungsweise „vorbehaltlich der Rechte des Papstes und des Patriarchen von Jerusalem" (excepto domino papa et patriarcha iherosolimitano) im Hinblick auf den Templermeister und seine Brüder.

Mit diesem Vorbehalt stand Tortosa im Spannungsverhältnis zwischen den beiden Patriarchen, ${ }^{44}$ was den Templern langfristig nur Recht sein konnte. Zwar nicht de iure, aber doch de facto, legte die Übereinkunft von i 52 die Grundlage für eine Art Templerbistum oder Templerherrschaft, mindestens aber für ein condominium, auch wenn dies den entsprechenden Prälaten wohl nie so richtig bewusst wurde. ${ }^{45}$ Durch den Verlust des Templerarchivs fehlen uns hier leider jene Details, die wir für die Johanniter und Margat, beziehungsweise das Bistum Vale-

43 Vgl. Riley-Smith, "The Templars," 285 (Anm. 6- I2) zu diesen Orten: marraclea (Maraclea), camelum (Kaimah), exerc (Eixserc), colea (La Colée), castrum novum (unbekannt), cratum (Krak des Chevaliers) und lacum (Akun).

44 Vgl. Rudolf Hiestand, "Templer- und Johanniterbistümer und -bischöfe im Heiligen Land," in Ritterorden und Kirche im Mittelalter, hrsg. v. Zenon Hubert Nowak, Ordines Militares. Colloquia Torunensia Historica IX (Toruń: Wydawnictwo Uniwersytetu Mikołaja Kopernika, I 997), I $43-$ I 62, hier I $47-$ I 48.

45 Ebd., I 48. 
nia, besitzen. ${ }^{46}$ Dass der Bischof von Tortosa die Templer, nicht aber die Johanniter, mit diesen neuen Rechten und Pflichten in seiner Stadt und seinem Bistum bedachte, hat Malcolm Barber damit erklärt, dass die Johanniter in der Grafschaft Tripolis bereits erhebliche Aufgaben übernommen und damit vielleicht ihre damaligen Kapazitätsgrenzen erreicht hatten, während die Templer zu dieser Zeit bereits einige für die zukünftige Verteidigung von Tortosa wichtige Burgen besassen, darunter auch Chastel Blanc. ${ }^{47}$ Ihre neue Stellung in Tortosa gab den Templern jedenfalls einen strategischen Vorteil an der nordsyrischen Küste, den die Johanniter erst I 87 durch den Erwerb von Margat wieder ausgleichen konnten. Schliesslich sollte man, Alain Demurger folgend, auf die Bedeutung von Tortosa als Heiligtum der Jungfrau Maria, der Ordenspatronin der Templer, hinweisen..$^{8}$ Sie erklärt auch die Templerexpedition zur Insel Ruad im frühen I 4. Jahrhundert, lag diese doch als Brückenkopf direkt gegenüber von Tortosa. ${ }^{49}$ Abgesehen davon bot Tortosa als Pilgerort lukrative Einkünfte, die der Stadt und ihren Stadtherren, also dem Bischof und den Templern, eine gewisse wirtschaftliche Stabilität in dieser Region garantierten. ${ }^{50}$

Die vertragliche Vereinbarung von i I 52 zwischen dem Bischof von Tortosa und den Templern war Malcolm Barber zufolge die ausführlichste ihrer Art für die Templer im lateinischen Osten. ${ }^{51}$ Das heisst allerdings nicht, wie Bernard Hamilton noch meinte, es gebe für das I 2. Jahrhundert keinerlei Hinweise auf Konflikte zwischen Templern und Bischöfen im Heiligen Land. ${ }^{52}$ Zwar war der Bischof von Tortosa zunächst nicht im Visier des Ordens, dafür aber sein nördlicher Nachbar, der Bischof von Valenia. I I 63 kam es zu einer urkundlich festgelegten „Eintracht“ (concordia) zwischen dem Bischof von Valenia und den Templern, ${ }^{53}$ was impliziert, das es zuvor zu einem Streit gekommen war, und sechs Jahre später ( I I69) be-

46 Ebd., I 48; Burgtorf, "Die Herrschaft," 29-32, 35-39; Burgtorf, "The Hospitaller Lordship," I 4-19, 24-30.

47 Barber, The Crusader States, 198.

48 Alain Demurger, Vie et mort de l'ordre du Temple: II20-I3I4 (Paris: Éditions du Seuil, I993, 3. Auflage), 67 .

49 Vgl. hierzu Jochen Burgtorf, "Die Templer auf Ruad (1300-1302)," in Ordines Militares Colloquia Torunensia Historica. Yearbook for the Study of the Military Orders 16 (20 I I) (Die Ritterorden in Umbruchs- und Krisenzeiten / The Military Orders in Times of Change and Crisis): 63-92.

so Vgl. Hamilton, The Latin Church, 285-286.

¿I Malcolm Barber, The New Knighthood: A History of the Order of the Temple (Cambridge: Cambridge University Press, I 994), 107.

s2 Hamilton, The Latin Church, ı 09: „There is no evidence of disputes between bishops and Templars in the twelfth century."

53 Codice, hrsg. v. Pauli, 40-4I Nr. XXXIX; Regesta Regni Hierosolymitani, hrsg. v. Röhricht, Nr. 38 I; RRRHD, Nr. 704. 
mühten sich beide Parteien bereits erneut zum Verhandlungstisch zur Schlichtung ihrer "langwährenden Streitigkeiten“ (multo tempore controversias), wobei der Bischof von Tortosa offenbar als Vermittler wirkte. ${ }^{54}$ Allerdings nahmen weder der Bischof von Valenia noch der Bischof von Tortosa am Dritten Laterankonzil teil, s5 dessen Kritik an Templern und Johannitern wegen ihrer Verletzung der Diözesanrechte ohnedies in der Theorie oder auf dem Pergament besser aussah, als sie sich in der Praxis in den durch den Ayyubidenherrscher Saladin zusehends bedrohten Kreuzfahrerstaaten durchsetzen liess.

Dass die I 152 in Tortosa geschaffene „Eintracht“ zwischen den Templern und dem Ortsbischof nicht ewig währen konnte, sollte jedoch bald deutlich werden. So kam I 225 der Paukenschlag in der Form eines Schreibens (Quotiens ea nostro apostolatui) Papst Honorius' III. an den Templermeister Peter von Montaigu und seine Ordensbrüder, ${ }^{56}$ wobei dessen Arenga noch relativ zahm ist: „Wann immer an unser Apostolat solcherlei Dinge über euch oder einen von euch von irgendwem herangetragen werden, die euren Ruhm bei den Menschen verdunkeln und das Gewissen vor Gott beschmutzen, dann sind wir umso enschlossener, euch und euer Haus mit den Armen aufrichtigerer Nächstenliebe zu umschlingen."57

Zunächst resümiert das Mandat die Klagen des Bischofs Durand von Tortosa. Die Templer verletzten die urkundlich festgelegte Teilung der Stadt und massten sich im Herrschaftsbereich der Kirche Rechte an. Sie schlossen „ein Stadttor, das der Kirche gehörte" (portam civitatis que ipsius est ecclesie specialis), nach Belieben und stellten dort Wächter auf. Sie proklamierten durch ihren Herold widerrechtlich ihre "Gerichtsbarkeit“ (bannum) im Stadtteil der Kirche. Sie behinderten

${ }_{4}$ Les Archives, la Bibliothèque et le Trésor de l'Ordre de Saint-Jean de Jérusalem à Malte, hrsg. v. Joseph Delaville Le Roulx, Bibliothèque des Écoles Françaises d'Athènes et de Rome 32 (Paris: Ernest Thorin, I883), I I2-II 3 Nr. XXIX; Regesta Regni Hierosolymitani, hrsg. v. Röhricht, Nr. 462; RRRHD, Nr. 822.

ss Vgl. die einschlägigen Konzilsteilnehmerlisten: Sacrorum conciliorum nova et amplissima collectio, hrsg. v. Mansi, 22: col. 21 5; Spicilegium, hrsg. v. D’Achéry, I: 637; Guillaume de Tyr, Chronique, hrsg. v. Huygens, 996 (XXI, 25 (26)); Regesta Regni Hierosolymitani, hrsg. v. Röhricht, Nr. 575; RRRHD, Nr. 1023.

56 Pierre-Vincent Claverie, L'Ordre du Temple en Terre Sainte et à Chypre au XIIIe siècle, Bd. II, Centre de recherche scientifique, Sources et études de l'histoire de Chypre LIII (Nikosia: Centre de recherche scientifique, 2005), 4I2-4I3 Nr. 2 (alle nachfolgenden Zitate aus diesem Schreiben von I 225 stammen aus dieser Edition); RRRHD, Nr. 1975. Vgl. Pierre-Vincent Claverie, Honorius III et l'Orient (I2I6-I227): Étude et publication de sources inédites des Archives vaticanes (ASV), The Medieval Mediterranean 97 (Leiden: Brill, 2013), 403-405 Nr. 89.

7 Claverie, L'Ordre, 2: 4I 2-4I 3 Nr. 2, hier 4 I 2: Quotiens ea nostro apostolatui de vobis vel vestrum aliquo referuntur que famam vestram denigrant apud homines et conscientiam maculant apud Deum tanto fortius consitutam [sic] quanto vos et domum vestram sincerioris brachiis amplexamur. 
dort den „Fleischmarkt“ (becariam), sowie den freien Verkauf von Getreide und Wein durch die Kaufleute. Sie hätten unter Missachtung der Rechte des Bischofs und des Heiligen Stuhls in ihrem eigenen Stadtteil „zwei neue Kirchen gebaut“ (duas ecclesias [...] de novo edificastis), in denen sie „durch griechische Priester, die sich weigerten, dem Bischof zu gehorchen“" (per Grecos presbyteros [...] qui eidem episcopo in aliquo respondere contempnunt), den Dienst tun liessen. Sie hätten die zwischen ihnen und der Kirche festgelegten Grenzen überschritten, nämlich das Gebiet der Kirche, in dem der Bischof von jener Zeit an die Herrschaft gehabt habe, als sie ihm einhundert Jahre zuvor und noch bevor die Templer dort ein Haus gehabt hätten, übertragen worden sei. Nach Aussage ihrer eigenen sarazenischen Bauern beraubten sie die Kirche täglich ihrer Einkünfte in der Stadt und ihres Anteils an den Zehnten im Bistum, und sie hielten einen der Kirche zustehenden Tribut von der Stadt Coeblum zurück. Wenn die Stadt unter ein kirchliches Interdikt gestellt werde, weigerten sich die Templer dies einzuhalten. Sie ignorierten die Pfarreirechte des Bischofs im Hinblick auf Chastel Blanc. Beispielsweise habe einer, der den Pfarreiangehörigen dort Salböl (crisma sanctum) und andere geistliche Sakramente darreiche, sie den Templern unrechtmässig verkauft. Und sie verletzten die zwischen ihnen und der Kirche geschlossenen Vereinbarungen (privilegia et alia instrumenta) im Hinblick auf Lehnsleute, Fischereirechte, Wälder und andere Dinge, was zeigt, dass es nach I I 52 noch zu weiteren Übereinkommen zwischen den Templern und dem Bischof von Tortosa gekommen sein muss, die leider nicht erhalten sind.

Angesichts dieser Zustände befahl Honorius III. den Templern, dem Bischof im Hinblick auf alles Genannte derart Genugtuung zu verschaffen, „dass kein Grund zur Klage mehr bestünde" (quod [...] nulla remaneat materia conquerendi). Abschliessend teilte er ihnen noch mit, er habe die Erzbischöfe von Tyrus und Cäsarea, sowie den Bischof von Akkon, angewiesen, dies durchzusetzen. Die Deutlichkeit dieser Gardinenpredigt tat offenbar ihre Wirkung, denn es wurden in Rom in der Folgezeit keine weiteren Klagen des Bischofs von Tortosa über die Templer mehr laut. ${ }^{8}$ Dabei hätten die Templer in den späten I $270 e r$ Jahren sogar Grund zur Gegenklage gehabt, denn als Bischof Paulus von Tripolis während des dortigen Bürgerkriegs bei den Templern seiner Stadt Zuflucht fand, empfahl Bischof Bartholomäus von Tortosa dem Fürsten Bohemund VII., das dortige Templerhaus zu belagern und seinen Amtskollegen mit Gewalt herauszuholen, 59 was

58 Hamilton, The Latin Church, 285-286.

s9 Bullarium Franciscanum Romanorum Pontificum, constitutiones, epistolas, ac diplomata continens, hrsg. v. Johannes Hyacinthus Sbaralea, Bd. III, A Clemente IIII ad Honorium IIII (Rom: Typis Sacrae Congregationis de Propaganda Fide, 1765 (Nachdruck: Santa Maria degli Angeli: Edizioni Porziuncola 1984)), 326-328 Nr. 45, hier 327: idem Princeps [...] dicto Tripolitano 
wohl eine Verletzung des Kirchenasyls gewesen wäre. Dass die Templer ebendiesen aufrührerischen Bischof von Tortosa dann I 29 I dennoch aus dem Heiligen Land in Sicherheit brachten, ${ }^{60}$ kann man schon als "grossmütig“ bezeichnen, zeigt aber letztlich, wie auch die nachfolgende Ruad Expedition, wie stark sich die Templer mit „ihrem“ Tortosa und dem dortigen Marienheiligtum im speziellen und ihrer Aufgabe zur Verteidigung des Heiligen Landes im allgemeinen identifizierten.

\section{Der Deutsche Orden und der Bischof von Hebron}

Schliesslich bleibt noch der Deutsche Orden und Hebron. ${ }^{61}$ Berühmt als letzte Ruhestätte der alttestamentarischen Patriarchen im judäischen Bergland südlich von Jerusalem, war Hebron vor seiner Eroberung durch den Ersten Kreuzzug kein Bistum gewesen. Es wurde erst I I 68 zu einem solchen erhoben und dem Patriarchen von Jerusalem unterstellt. ${ }^{62}$ Nach der Schlacht von Hattin i I 87 blieb es vakant, bis es Papst Innozenz IV. um die Mitte des I 3. Jahrhunderts als Titularbistum wiederbelebte, ${ }^{63}$ dessen Amtsinhaber in Akkon residierte, wo er dann auch auf den Deutschen Orden traf. ${ }^{64}$

Anfang I 252 schickte Innozenz IV. dem Bischof Arnold von Lydda und dem Elekten von Bethlehem, Gottfried von Praefectis, das Mandat Cum ecclesiarum

Episcopo promisisset eamdem Domum dictae Militiae Templi, jura, \& libertates ipsius, postquam de illa idem Tripolitanus Episcopus recederet, custodire [...] idem Episcopus Anteraden [sis]. Principi memorato in praesentia multorum fidedignorum suggessit, ut dictum Tripolitanum Episcopum capi faceret, \& carceri deputari.

60 Hamilton, The Latin Church, 240-24I; Kennedy, “Tortosa (Syria)," I I 86.

${ }_{61} \mathrm{Zu}$ Hebron, vgl. unter anderem Fedalto, La Chiesa, I: I 48-I 49; ders., La Chiesa, 2: I 28; Denys Pringle, The Churches of the Crusader Kingdom of Jerusalem: A Corpus, Bd. I, $A-K$ (excluding Acre and Jerusalem) (Cambridge: Cambridge University Press, 1993), 223-239; Kennedy, Crusader Castles, 22; Pringle, Secular Buildings, 50; Brett Edward Whalen, "Hebron," in The Crusades, hrsg. v. Murray, 2: 563-564.

62 Papsturkunden für Kirchen im Heiligen Lande, hrsg. v. Hiestand, 19-20, 292-293.

63 Fedalto, La Chiesa, 2: I 28; Hamilton, The Latin Church, 266, 298-299; Pringle, The Churches, I: $225-228$.

${ }^{64}$ Zum Deutschen Orden im Königreich Jerusalem, vgl. Klaus Militzer, Von Akkon zur Marienburg: Verfassung, Verwaltung und Sozialstruktur des Deutschen Ordens, IIgo-I309, Quellen und Studien zur Geschichte des Deutschen Ordens 56, Veröffentlichungen der Internationalen Historischen Kommission zur Erforschung des Deutschen Ordens 9 (Marburg: N. G. Elwert Verlag, I 999), I 66-1 72; sowie, in hebräischer Sprache publiziert, Shlomo Lotan, The Teutonic Order in the Latin Kingdom of Jerusalem: The Development of the Teutonic Military Order I Igo-1309. Mutual Relations between the Latin East and Europe (Tel Aviv: Ofir Bikurim, 20 I 2). 
dampnis. ${ }^{65}$ In der Arenga heisst es: „Wenn wir auch den Schäden der Kirchen nicht überall durch Vorbeugung entgegenwirken können, ziemt es sich doch, damit die Güter derselben wenigstens nicht mit Recht zerstreut werden, dass wir gegen die Schädigung mit geeignetem Heilmittel zu Hilfe eilen. ${ }^{\text {“6 }}$ Der Bischof von Hebron, der Zisterzienser Bartholomäus von Fossanova, ${ }^{67}$ und sein Kapitel hätten dem Papst mitgeteilt, dass „etliche Güter der Kirche von Hebron entfremdet und zerstreut worden seien" (multa de bonis Ebronensis ecclesie alienata sint illicite et distracta). Daher weise der Papst die beiden Empfänger an, die besagten Güter „dem Recht und Besitz" (ad ius et proprietatem) der Kirche von Hebron zurückzuführen, sofern dem nicht irgendwelche Besitz- oder Übertragungstitel oder verhängte Strafen oder zwischenzeitliche Rechtssprüche und päpstliche Bestätigungen und die auf dem Vierten Laterankonzil ( I 2 I s) erlassene 37. Konstitution (de duabus dietis), also das Verbot der Vorladung vor ein Gericht, das über zwei Tagesreisen weit entfernt sei, ${ }^{68}$ entgegenstünden. Ausserdem sollten sie diejenigen, die widersprächen, mit kirchlichen Strafen belegen.

Entweder war die Post aussergewöhnlich langsam, oder der Papst hatte vergessen, dass man im Heiligen Land durch die Anwesenheit König Ludwigs IX. von Frankreich abgelenkt war, oder aber die Empfänger drückten sich vor ihrer Verantwortung. Jedenfalls meldeten sie sich erst über ein Jahr später zu Wort, als sie den Empfang des päpstlichen Mandats dem Heiliggrabkanoniker Matthäus anzeigten: ${ }^{69}$ sie selbst seien zur Zeit bei Jaffa "im christlichen Heer" (in exercitu christiano), wo sich nämlich der französische König gerade ebenfalls aufhielt, ${ }^{70}$ weswegen sie die Hebroner Klage nicht persönlich untersuchen könnten. Daher delegierten sie ihn, also den Heiliggrabkanoniker Matthäus, „behielten sich aber die endgültige Entscheidung vor" (diffinitiva nobis sentencia reservata). Er solle

65 Tabulae, hrsg. v. Strehlke, 8 I Nr. I I I (alle nachfolgenden Zitate aus diesem Schreiben von 1252 stammen aus dieser Edition); vgl. Regesta Regni Hierosolymitani, hrsg. v. Röhricht, Nr. I 203 (Anm. 2). Zu Bischof Arnold von Lydda, vgl. Fedalto, La Chiesa, 2: I 43; zum Elekten von Bethlehem, Gottfried von Praefectis, vgl. ebd., 2: 58.

66 Tabulae, hrsg. v. Strehlke, 8 I Nr. I I : Cum ecclesiarum dampnis nequeamus passim occurrere precavendo, quin earum bona quamquam minus licite distrahantur, convenit, ut dampnificationi congruo remedio succurramus.

${ }_{7} \mathrm{Zu}$ diesem, vgl. Fedalto, La Chiesa, 2: 28.

68 Conciliorum Oecumenicorum Decreta, hrsg. v. Alberigo, 227-228, Konstitution 37: De litteris non impetrandis ultra duas diaetas et sine speciali mandato.

69 Tabulae, hrsg. v. Strehlke, 81-82 Nr. 102; Regesta Regni Hierosolymitani, hrsg. v. Röhricht, Nr. I 203.

70 Vgl. Reinhold Röhricht, Geschichte des Königreichs Jerusalem (IIO0-I29I) (Innsbruck: Verlag der Wagner'schen Universitäts-Buchhandlung, i 898 (Nachdruck: Amsterdam: Verlag M. Hakkert, I 966)), 887-890. 
jene vorladen, die vorgeladen werden müssten, die genannten Fragen untersuchen und dafür sorgen, dass die ausreichend studierten Angelegenheiten ihnen dann brieflich mit einer Liste der Betreffenden zukommen würden. ${ }^{71}$

Die Mühlen der Justiz mahlten vor sich hin, und so kam die Angelegenheit ein halbes Jahr später in Akkon endlich zur Verhandlung unter dem Vorsitz des bereits genannten Kanonikers Matthäus, der zu diesem Zweck das päpstliche Mandat und sein eigenes Subdelegationsmandat vorlegte. ${ }^{72}$ Der Bischof von Hebron beschuldigte „den Deutschordensmeister Poppo von Osterna (von Osternohe) und dessen Konvent" (religiosum virum fratrem Popum magistrum sancte Marie Theuthonicorum et eius conventum), beziehungsweise deren Prokurator Walter, ihr Orden habe zum Schaden der Hebroner Kirche gewisse Häuser unrechtmässig besetzt, „die in der Montmusard Vorstadt von Akkon, im Gerbereiviertel, auf dem Gebiet der Kirche von Hebron, nahe der Dreieinigkeitskirche und neben dem Haus des Gerbers Philipp" stünden (in burgo Montis Musardi in Tauaria [sic] sitas in territorio ecclesie Ebronensis prope ecclesiam sancte Trinitatis et iuxta domum Philippi Tanaor), sowie ein kleines Gewölbe in der Sankt-Katharinen Strasse, das der Ritter Dietrich von Oufholt der Kirche von Hebron geschenkt habe und dessen Grenzen in einer beigebrachten Urkunde dargelegt seien. Trotz der Sedisvakanz von 65 Jahren hatte also jemand die Hebroner Urkunden aufgehoben, möglicherweise der Patriarch von Jerusalem, der ja seit I I 9 I auch in Akkon residierte.

Diese Objekte, so der Bischof, gehörten rechtmässig seiner Kirche und „er sei bereit, ihnen die entsprechenden richterlichen Bescheide vorzuzeigen“ (et paratus est dictus episcopus eis ostendere iudicis arbitrio). Der subdelegierte Richter möge die Objekte ihm und seiner Kirche zuerkennen; den Deutschen Orden zur Rückgabe der Objekte, sowie der dort über zwanzig Jahre hinweg empfangenen Einkünfte zwingen, die er auf 3000 sarazenische Byzantiner schätze; und ihm die Prozesskosten erstatten. In den Augen des Deutschen Ordens war dies freilich bischöfliches Wunschdenken, und so antwortete der Deutschordensprokurator Walter, der vorsitzende Kanoniker Matthäus habe keinerlei Jurisdiktion in der Sache, da der Deutsche Orden in keinem der Delegationsmandate namentlich genannt sei. Der Orden könne aufgrund seiner päpstlichen Privilegien nicht vermittels von Briefen des Papstes gerichtlich belangt werden, in denen er nicht namentlich genannt sei. Als Beweis lege er die folgenden Privilegien vor, die dies bestätigten, nämlich erstens die von Papst Gregor IX. 1227 an den Deutschordensmeister Hermann von

${ }_{71}$ Tabulae, hrsg. v. Strehlke, 8 I -82 Nr. 102.

72 Ebd., 82-84 Nr. 104 (alle nachfolgenden Zitate aus diesem Prozessbericht von I 253 stammen aus dieser Edition); Regesta Regni Hierosolymitani, hrsg. v. Röhricht, Nr. I 207. Vgl. Pringle, The Churches, 4: 16, 5I-52. 
Salza adressierte Ausfertigung von Vestra religio cuius bonus odor, sowie zweitens die von Papst Innozenz IV. I 247 an den Deutschen Orden adressierte Ausfertigung von Quieti vestre providere volentes. ${ }^{73}$

Dann aber, so heisst es weiter in diesem Prozessbericht, sei man „zum Wohle des Friedens und der Eintracht" (pro bono pacis et concordie), und zumal es für beide Parteien „lästig und teuer“ (honerosum et sumptuosum) gewesen wäre, über einen Schiedsspruch zu zanken, wie folgt übereingekommen: der Meister und Konvent hätten versprochen, dem Bischof und seinem Kapitel oder deren Boten für die genannten Objekte jährlich am Feste Mariä Himmelfahrt, also dem I 5 . August, sieben Byzantiner zu zahlen, womit dieser Rechtsstreit als beendet angesehen werden sollte, unter Androhung einer Geldbusse von 500 Mark bei Zuwiderhandlung. Die Umstände, unter denen der Deutsche Orden diese Immobilien im Gerbereiviertel rund zwanzig Jahre zuvor in Besitz genommen hatte, sind leider nicht bekannt.

Jedenfalls mussten sich die Bischöfe von Hebron im folgenden nach anderen Geldquellen umsehen, lebten aber wohl zumeist von der Hand in den Mund, ${ }^{74}$ wobei die neuerliche Besetzung ihres alten Bistums durch die Mamluken ( I 258 ), die Juden und Christen den Zutritt zum dortigen heiligen Bezirk untersagten ( 1266 ), ihre Position weiterhin geschwächt haben dürfte. ${ }^{75}$ Was den Deutschen Orden anlangt, konnten die Bischöfe von Hebron immerhin ihre Vidimierungsund Transsumierungsfähigkeiten vermarkten, so geschehen I 254 für eine ältere

73 Laut Regesta Regni Hierosolymitani, hrsg. v. Röhricht, Nr. I 207 (Anm. 6-7), sind die beigebrachten Papstprivilegien die folgenden: I 2. Juni 1227 (Vestra religio cuius bonus odor): Tabulae, hrsg. v. Strehlke, 340 Nr. 4I 6; sowie I 3 . Juni I 247 (Quieti vestre providere volentes): ebd., 369 Nr. 5 I 3. Das erstere (I 227) wiederholt, laut ebd., 340, das entsprechende Privileg Papst Honorius' III. von I 22 I; das letztere ( 1247 ) wiederholt, laut ebd., 369 , das entsprechende Privileg Papst Gregors IX. von I 235. Man hätte sicher auch frühere Ausfertigungen von Vestra religio cuius bonus odor Papst Honorius' III. vorlegen können, beispielsweise von I 22 I : ebd., 28 I - 282 Nr. 309; I 223 : ebd., 324 Nr. 373; oder I 226: ebd., 33 I Nr. 398. Aber es schien vielleicht angeratener eine zeitnähere Ausfertigung beizubringen. Das gleiche gilt für Quieti vestre providere volentes, das bereits I 227 durch Gregor IX. ausgestellt worden war: ebd., 346-347 Nr. 436; und das 1235 von ihm wiederholt worden war: ebd., 354 Nr. 465. In diesem Fall schien die Ausfertigung Innozenz' IV. von I 247 angesagt, hatte dieser Papst doch die Untersuchung der Angelegenheiten des Hebroner Bischofs erst angeordnet.

74 So Hamilton, The Latin Church, 299.

75 Vgl. Peter Thorau, The Lion of Egypt: Sultan Baybars I and the Near East in the Thirteenth Century, übers. v. Peter M. Holt (London-New York: Longman, I 992), 56, I 67. 
Urkunde Kaiser Friedrichs II.. ${ }^{76}$ sowie I 277 und I 28 I für päpstliche Privilegien. ${ }^{77}$ In einer Urkunde von I 265 bezeugte der Großpräzeptor des Deutschen Ordens im Gegenzug eine Übereinkunft zwischen dem Bischof von Hebron und den Johannitern. ${ }^{7}$ Eine Hand wusch eben schon damals die andere. Die umstrittenen Immobilien im Gerbereiviertel wurden I 273 von den Johannitern für I 700 sarazenische Byzantiner erstanden, wobei der Bischof von Hebron eine Ablösesumme erhielt. Die Johanniter wollten sich wohl nicht mit ihm herumschlagen. Allerdings darf man den Bischof von Hebron, angesichts des Falls von Akkon I291, rein rechnerisch wohl als den Gewinner dieser Transaktion ansehen. Jedoch waren die Besitz- und Anspruchsverhältnisse im Hinblick auf die besagten Immobilien selbst 1273 noch so kompliziert, dass die gesamte Transaktion in mindestens fünf separaten rechtlichen und urkundlich niedergelegten Schritten abgewickelt werden musste, an denen etliche Personen beteiligt waren, darunter der König von Jerusalem und Zypern, der Patriarch von Jerusalem (gleichzeitig päpstlicher Legat und Verwalter des Bistums Akkon), der Elekt von Nikosia, logischerweise

76 Die Urkunden, hrsg. v. Mayer, 3: I $107-1$ I 10 Nr. 66 I (Urkunde Kaiser Friedrichs II. vom [ I.-20.] April I 229); laut ebd., I I 07, vidimiert (am I 7. Juli I 254) durch den Bischof von Hebron, Bartholomäus (von Fossanova), und den Erzbischof Ägidius von Tyrus; Regesta Regni Hierosolymitani, hrsg. v. Röhricht, Nr. I 1 I ; RRRHD, Nr. 2 I 06.

77 I 277: Tabulae, hrsg. v. Strehlke, 384 Nr. 545 (Vestra religio cuius bonus odor, Urkunde Papst Alexanders IV. vom 3. Juni I 257), laut Anmerkung, ebd., von Bischof Gottfried von Hebron zusammen mit Erzbischof Matthäus von Cäsarea transsumiert (am 3 I. August I277); Regesta Regni Hierosolymitani, hrsg. v. Röhricht, Nr. I4I 5, I417. I 28 I: Tabulae, hrsg. v. Strehlke, 296-297 Nr. 328 (Quia plerumque veritatis integritas, Urkunde Papst Honorius' III. on I 8. Januar I 22 I), laut Anmerkung, ebd., 297, von Bischof Gottfried von Hebron zusammen mit dem Patriarchen Elias von Jerusalem und dem Erzbischof Ranulf von Nikosia transsumiert (am I 2. September I 28 I); Regesta Regni Hierosolymitani, hrsg. v. Röhricht, Nr. I 44 I.

78 Valletta, National Library of Malta, Archives of the Order of Malta I, I 8, 5; Les Archives, hrsg. v. Delaville Le Roulx, Additions, 229-230 Nr. I (dort nur Zeugenliste und Datum: fratre Gernest, magno preceptore domus Hospitalis Sancte Marie Theutonicorum); Cartulaire général de l'Ordre des Hospitaliers de S. Jean de Jérusalem (II00-I3IO), hrsg. v. Joseph Delaville Le Roulx, Bd. III, I26I-I300 (Paris: Ernest Leroux, I 899), 96-97 Nr. 3 I 20 (dort ebenfalls nur Zeugenliste und Datum); Regesta Regni Hierosolymitani, hrsg. v. Röhricht, Nr. I 337 . Laut ebd., 350, ist dieser Großpräzeptor Gernest vielleicht „Arnestus de Vulven (Wolfen in Hassia sive Wulfen prope Monasterium) “, der am I 2. April eines ungenannten Jahres starb; vgl. dazu Max Perlbach, "Deutsch-Ordens-Necrologe," Forschungen zur Deutschen Geschichte I 7 ( I 877): 357-37 I, hier 364 (Altenbiesener Nekrolog): Id. Apr. [...] obiit frater Arnestus de Vulven, qui fuit marchalcus in Akon. Allerdings sieht der Name in der Handschrift dieser im Original erhaltenen Urkunde eher aus wie Eernest, zumal der Buchstabe „G“ dort anders geschrieben ist. Bei Frank Milthaler, Die Großgebietiger des Deutschen Ritterordens bis 1440, Schriften der Albertus-Universität, Geisteswissenschaftliche Reihe, 26 (Königsberg-Berlin: Ost-Europa-Verlag, 1940), 33-42, ist dieser Funktionsträger weder in der Liste der Großpräzeptoren noch in der Liste der Marschälle verzeichnet. 
der Bischof von Hebron, der Großpräzeptor des Deutschen Ordens, der örtliche Syndikus und Prokurator des Deutschen Ordens, der Johanniterthesaurar und ein Bürger der Stadt Akkon. ${ }^{9}$

Als weitere Einnahmequelle kam für die Bischöfe von Hebron schliesslich noch das Ausstellen von Ablässen zugunsten des Deutschen Ordens in Frage. I 283 gewährte der Bischof von Hebron, nunmehr der in Akkon residierende Dominikaner Gottfried, allen Christen, die die Elisabethskirche des Deutschen Ordens in Marburg besuchen würden, und zwar zu deren Festen, ${ }^{8 \circ}$ deren Oktaven, und zur Einweihung, einen Ablass von vierzig Tagen.${ }^{81}$ Den gleichen Ablass gewährten die Bischöfe von Beirut, Tiberias, Linköping und Bethlehem, sowie zu anderer Zeit und an anderem Ort die Erzbischöfe von Siponto in Apulien und Zara in Kroatien. ${ }^{82}$ Wie Axel Ehlers dargelegt hat, war es wohl Burchard von Schwanden selbst, der I 283 , als er noch Komtur von Marburg war, auf jener Reise ins Heilige Land, die mit seiner Hochmeisterwahl enden sollte, diese Ablässe erwarb. ${ }^{83}$ Im gleichen Jahr stellte derselbe Bischof Gottfried von Hebron zusammen mit einigen Amts-

79 Erstens, vor dem 9. August I 273: Die Urkunden, hrsg. v. Mayer, 3: I $253-1254$ Nr. 7 I 6; zweitens, am 9. August I 273: Cartulaire, hrsg. v. Delaville Le Roulx, 3: 296-297 Nr. 35 I 4; Regesta Regni Hierosolymitani, hrsg. v. Röhricht, Nr. I389; drittens, am I I. August I 273: Tabulae, hrsg. v. Strehlke, I I 6- I I 8 Nr. I 26; Regesta Regni Hierosolymitani, hrsg. v. Röhricht, Nr. I 390 ; viertens, am 21. August I 273: Marseilles, Archives départementales (Bouches-du-Rhône), Ordre de Malte 56 H 68 (Inventaire de Manosque a. I 53 I), fol. 57 I (66 B); fünftens, am 25. August I 273: Cartulaire, hrsg. v. Delaville Le Roulx, 3: 297-298 Nr. 35 I 5; Regesta Regni Hierosolymitani, hrsg. v. Röhricht, Nr. I 39 I.

80 Die Feste der Heiligen Elisabeth sind ihr Todestag (17. November I23 I), der Tag ihrer Beisetzung (19. November I 23 I) und der Tag ihrer Heiligsprechung (27. Mai I 235). Vgl. hierzu nun auch Anette Löffler, "Elisabeth in der Liturgie des Deutschen Ordens," in Elisabeth von Thüringen und die neue Frömmigkeit in Europa, hrsg. v. Christa Bertelsmeier-Kierst, Kulturgeschichtliche Beiträge zum Mittelalter und zur frühen Neuzeit I (Frankfurt am Main: Peter Lang, 2008), I $33-149$.

81 Hessisches Urkundenbuch, Erste Abtheilung: Urkundenbuch der Deutschordens-Ballei Hessen, hrsg. v. Arthur Wyss, Bd. I, I207-I299, Publicationen aus den K. Preussischen Staatsarchiven III (Leipzig: Verlag von S. Hirzel, I 879), 306 (Anm. 4 zu Nr. 409): Frater Gaufridus de ordine Predicatorum ep [iscopus]. Ebronensis; Regesta Regni Hierosolymitani, hrsg. v. Röhricht, Nr. I 449 (2. Teil); Axel Ehlers, Die Ablasspraxis des Deutschen Ordens im Mittelalter, Quellen und Studien zur Geschichte des Deutschen Ordens 64 (Marburg: N. G. Elwert Verlag, 2007), 443 Nr. 4839 .

82 Hessisches Urkundenbuch, hrsg. v. Wyss, I: 306 Nr. 409, sowie ebd., 306 (Anm. I-3, 5-6); Regesta Regni Hierosolymitani, hrsg. v. Röhricht, Nr. I 449 (2. Teil); Ehlers, Die Ablasspraxis, 442-443 Nr. 483 I, 4835-4838, 484I. Vgl. Thomas Eck, Die Kreuzfahrerbistümer Beirut und Sidon im I2. und I3. Jahrbundert auf prosopographischer Grundlage, Kieler Werkstücke, Reihe C: Beiträge zur europäischen Geschichte des frühen und hohen Mittelalters 3 (Frankfurt am Main: Peter Lang, 2000), 90 (mit Anm. 563-565).

83 Ehlers, Die Ablasspraxis, 24. 
kollegen auch eine besonders schöne Sammelindulgenz für die Grazer Kunigundenkirche des Deutschen Ordens aus. Er rangierte dabei an erster Stelle, noch vor dem Erzbischof von Nikosia, allerdings nur deswegen, weil er nun auch als Vikar der Patriarchen Elias von Jerusalem fungierte, weswegen er auch den doppelten Ablass gewähren durfte, trotzdem aber mit seinem eigenen Bischofssiegel siegeln musste. ${ }^{84}$ Der Streit zwischen seinem Amtsvorgänger und dem Deutschen Orden um jene Immobilien in der Montmusard Vorstadt war unterdessen längst Vergangenheit und trübte keineswegs das beiderseitige Verhältnis, was die aufgrund der Quellenlage oftmals so dramatisch wirkenden Auseinandersetzungen zwischen Ritterorden und Ortsbischöfen vielleicht doch etwas relativiert.

Trotz aller Konflikte waren Bischöfe und Ritterorden, ob sie es wollten oder nicht, Glieder ein und desselben Leibes. ${ }^{85}$ Die dialektische Abfolge von Aktion, Reaktion und Kompromiss lässt sich dabei in den Kreuzfahrerstaaten immer wieder beobachten ${ }^{86}$ wobei die Kompromissbereitschaft zum einen sicherlich vom Streitgegenstand selbst abhing, ${ }^{87}$ zum anderen aber auch eindeutig von den dramatis personae, den jeweiligen Akteuren. Der in den entsprechenden Urkunden regelmässig erscheinende Begriff der concordia („Eintracht“) unterstreicht dabei, dass man sich seiner biblischen Verantwortung bewusst war und sich dieser auch stellte.$^{88} \mathrm{~W}$ ie die oben angerissenen Fallstudien zeigen, wurden die Ritterorden in die regionalen kirchlichen Strukturen der Kreuzfahrerstaaten zunächst unter aktiver Mitwirkung der Bischöfe selbst eingebunden. Zu Auseinandersetzungen mit den

${ }_{4}$ Wien, Deutschordenszentralarchiv (DOZA), Urkunden, Nr. 91 0, monasterium.net, zugegriffen am 2r. März 2019, http://monasterium.net/mom/AT-DOZA/Urkunden/910/charter; Die Urkunden des Deutsch-Ordens-Centralarchives zu Wien, hrsg. v. Eduard Gaston Graf von Pettenegg, Bd. I, II70-I809 (Prag-Leipzig: F. Tempsky und G. Freytag, i 887), I 59-160 Nr. 6 I 8 (a 530); Regesta Regni Hierosolymitani, hrsg. v. Röhricht, Nr. I 45 I; Ehlers, Die Ablasspraxis, I 5 I (mit Anm. 464), 45 I Nr. 5304; vgl. ebd., I 24 (Anm. 275); Die Urkunden des Deutschordens-Zentralarchivs in Wien: Regesten, hrsg. v. Udo Arnold und Marian Tumler, Teilband I, II22-Januar 1313, Quellen und Studien zur Geschichte des Deutschen Ordens Band 60/I, Veröffentlichungen der Internationalen Historischen Kommission zur Erforschung des Deutschen Ordens Band I I/I (Marburg: N. G. Elwert Verlag, 2006), Nr. 9 I o. Vgl. Eck, Die Kreuzfahrerbistümer, 90-9I (mit Anm. 565).

$85 \mathrm{Zu}$ einer ähnlichen Einschätzung gelangt Toomaspoeg, "The Military Orders," I 20.

86 Vgl. Riley-Smith, The Knights, 420.

87 Vgl. Krämer, Dämonen, 604.

88 Vgl. Biblia Sacra iuxta Vulgatam versionem, instr. Robert Weber, praep. Roger Gryson (Stuttgart: Deutsche Bibelgesellschaft, 2007, 5. Auflage), Actus Apostolorum 4:32a: Multitudinis autem credentium erat cor unum et anima una. 
Bischöfen kam es dort primär aufgrund der den Ritterorden verliehenen päpstlichen Privilegien, weil die Ritterorden dieselben nach Auffassung der Bischöfe missbrauchten. All dies darf aber nicht den Blick darauf verstellen, dass der Ritterordensklerus einen wichtigen Beitrag zur Seelsorge in den Bistümern leistete, und dass die Ritterorden durch ihren karitativen Einsatz, ihre militärische Präsenz und ihre infrastrukturellen Massnahmen die Arbeit der Ortsbischöfe oftmals erst ermöglichten.

In Galiläa haben wir begonnen, also kehren wir abschliessend auch noch einmal dorthin zurück. Einer Legende zufolge wurde die Santa Casa, das Haus der Jungfrau Maria in Nazareth, als Akkon I 29 I von den Mamluken belagert wurde, von Engeln nach Trsat im heutigen Kroatien gerettet, von wo aus es wenige Jahre später an seinen endgültigen Bestimmungsort nach Loreto nahe der Adriatischen Küste in Italien transferiert wurde. Dies hat Martin Rheinheimer wie folgt kommentiert: „Niemand rechnete mehr mit einer Rückeroberung Galiläas. Die heiligen Stätten waren verloren, aber die Pilger fanden ein neues Ziel. ${ }^{\text {‘9 }}$ In der Rückschau mag dies stimmen, jedoch zeigen die Aktivitäten der Ritterorden im späten I 3. und frühen I 4. Jahrhundert, seien es die der Johanniter auf Zypern und Rhodos, die der Templer auf Zypern und Ruad, oder auch die des Deutschen Ordens in Venedig und anderswo im Mittelmeerraum, dass die Ritterorden dem Heiligen Land verbunden blieben, dem sie letztlich ja ihre Namen und damit auch ihre Identität verdankten.

\section{PRIMARY SOURCES:}

Marseilles. Archives départementales (Bouches-du-Rhône), Ordre de Malte 56 H 68 (Inventaire de Manosque a. I 53 I), fol. 57 I (66 B); fol. 705 (94 Z).

Valletta. National Library of Malta, Archives of the Order of Malta I, I, 29; I, 3, 25; I, 6, 2; I, I 8, 5 .

Wien. Deutschordenszentralarchiv (DOZA), Urkunden, Nr. 910. monasterium.net, zugegriffen am 21. März 2019, http://monasterium.net/mom/AT-DOZA/Urkun$\mathrm{den} / 910 /$ charter.

Les Archives, la Bibliothèque et le Trésor de l'Ordre de Saint-Jean de Jérusalem à Malte. Herausgegeben von Joseph Delaville Le Roulx. Bibliothèque des Écoles Françaises d'Athènes et de Rome 32. Paris: Ernest Thorin, I 883.

Biblia Sacra iuxta Vulgatam versionem. Instruxit Robert Weber, praeparavit Roger Gryson. Stuttgart: Deutsche Bibelgesellschaft, 2007, 5. Auflage.

89 Rheinheimer, Das Kreuzfabrerfürstentum, 260. 
Bullarium Franciscanum Romanorum Pontificum, constitutiones, epistolas, ac diplomata continens. Bd. III. A Clemente IIII ad Honorium IIII. Herausgegeben von Johannes Hyacinthus Sbaralea. Rom: Typis Sacrae Congregationis de Propaganda Fide, 1765 (Nachdruck: Santa Maria degli Angeli: Edizioni Porziuncola I 984).

Cartulaire général de l'Ordre des Hospitaliers de S. Jean de Jérusalem (IIoo-I3IO). Bd. I. II00-I200. Herausgegeben von Joseph Delaville Le Roulx. Paris: Ernest Leroux, I 894.

Cartulaire général de l'Ordre des Hospitaliers de S. Jean de Jérusalem (IIO0-I3IO). Bd. II. I 200-I 260. Herausgegeben von Joseph Delaville Le Roulx. Paris: Ernest Leroux, 1897.

Cartulaire général de l'Ordre des Hospitaliers de S. Jean de Jérusalem (IIoo-I3IO). Bd. III. I26I-I300. Herausgegeben von Joseph Delaville Le Roulx. Paris: Ernest Leroux, I 899.

Claverie, Pierre-Vincent. L'Ordre du Temple en Terre Sainte et à Chypre au XIIIe siècle. Bd. II. Centre de recherche scientifique, Sources et études de l'histoire de Chypre LIII. Nikosia: Centre de recherche scientifique, 2005.

Claverie, Pierre-Vincent. Honorius III et l'Orient (I2I6-1227): Étude et publication de sources inédites des Archives vaticanes (ASV). The Medieval Mediterranean 97. Leiden: Brill, 2013.

Codice diplomatico del sacro militare ordine Gerosolimitano oggi di Malta. Herausgegeben von Sebastiano Pauli. Lucca: Salvatore e Giandomenico Marescandoli, 1733.

Conciliorum Oecumenicorum Decreta. Herausgegeben von Giuseppe Alberigo, Periclīs-Petros Ioannou, Claudio Leonardi und Hubert Jedin. Basel-Barcelona-Freiburg-Rom-Wien: Herder, I 962.

Guillaume de Tyr. Chronique. Herausgegeben von Robert B. C. Huygens. Identifizierung der historischen Quellen und Datierungen von Hans Eberhard Mayer und Gerhard Rösch. Corpus Christianorum, Continuatio Mediaevalis, LXIII-LXIII A. Turnhout: Brepols, i 986.

Hessisches Urkundenbuch, Erste Abtheilung: Urkundenbuch der Deutschordens-Ballei Hessen. Bd. I. I207-I299. Herausgegeben von Arthur Wyss. Publicationen aus den K. Preussischen Staatsarchiven III. Leipzig: Verlag von S. Hirzel, i 879.

Lettres de Jacques de Vitry (II60/II70-I240), évêque de Saint-Jean-d'Acre. Herausgegeben von Robert B. C. Huygens. Leiden: Brill, i 960.

Papsturkunden für Templer und Johanniter: Archivberichte und Texte. Herausgegeben von Rudolf Hiestand. Vorarbeiten zum Oriens Pontificius I, Abhandlungen der Akademie der Wissenschaften in Göttingen, Philologisch-Historische Klasse, Dritte Folge 77. Göttingen: Vandenhoeck \& Ruprecht, 1972.

Papsturkunden für Templer und Johanniter. Neue Folge. Herausgegeben von Rudolf Hiestand. Vorarbeiten zum Oriens Pontificius II, Abhandlungen der Akademie der Wissenschaften in Göttingen, Philologisch-Historische Klasse, Dritte Folge I 35. Göttingen: Vandenhoeck \& Ruprecht, I 984.

Papsturkunden für Kirchen im Heiligen Lande. Herausgegeben von Rudolf Hiestand. Vorarbeiten zum Oriens Pontificius III, Abhandlungen der Akademie der Wissen- 
schaften in Göttingen, Philologisch-Historische Klasse, Dritte Folge I 36. Göttingen: Vandenhoeck \& Ruprecht, I 985.

Perlbach, Max. "Deutsch-Ordens-Necrologe." Forschungen zur Deutschen Geschichte 17 ( I 877): 357-37 I.

Regesta Regni Hierosolymitani (MXCVII-MCCXCI) mit Additamentum. Herausgegeben von Reinhold Röhricht. Innsbruck: Libreria Academica Wagneriana, I 893 und I 904. Revised Regesta Regni Hierosolymitani Database, zugegriffen am 2 I. März 201 9, http:// www.crusades-regesta.com [abgekürzt als: RRRHD].

Riley-Smith, Jonathan. "The Templars and the Castle of Tortosa in Syria: An Unknown Document Concerning the Acquisition of the Fortress." The English Historical Review 84, no. 33 I (1 969): 278-288.

Sacrorum conciliorum nova et amplissima collectio. Bd. XXII. Herausgegeben von Giovanni Domenico Mansi. Venedig: Apud Antonium Zatta, I 778.

Spicilegium sive Collectio veterum aliquot scriptorum: Nova Editio. Bd. I. Herausgegeben von Luc d'Achéry, Étienne Baluze, Edmond Martène und Louis François Joseph de la Barre. Paris: Apud Montalant, 1723.

Tabulae ordinis Theutonici ex tabulari regii Berolinesis codice potissimum. Herausgegeben von Ernst Strehlke. Berlin: Weidmann, i 869 (Nachdruck: mit einer Einleitung von Hans Eberhard Mayer: Toronto: University of Toronto Press, I 975).

Die Urkunden des Deutsch-Ordens-Centralarchives zu Wien. Bd. I. I170-I809. Herausgegeben von Eduard Gaston Graf von Pettenegg. Prag-Leipzig: F. Tempsky und G. Freytag, i 887.

Die Urkunden des Deutschordens-Zentralarchivs in Wien: Regesten. Teilband I. II22-Januar I313. Herausgegeben von Udo Arnold und Marian Tumler. Quellen und Studien zur Geschichte des Deutschen Ordens Band 6o/I, Veröffentlichungen der Internationalen Historischen Kommission zur Erforschung des Deutschen Ordens Band I I/ /I. Marburg: N. G. Elwert Verlag, 2006.

Die Urkunden der lateinischen Könige von Jerusalem. Bd. I-IV. Herausgegeben von Hans Eberhard Mayer. Altfranzösische Texte erstellt von Jean Richard. Monumenta Germaniae Historica, Diplomata Regum Latinorum Hierosolymitanorum. Hannover: Hahnsche Buchhandlung, 20 г.

\section{SECONDARY SOURCES:}

Antweiler, Wolfgang. Das Bistum Tripolis im I2. und I3. Jahrhundert: Personengeschichtliche und strukturelle Probleme. Studia humaniora, Düsseldorfer Studien zu Mittelalter und Renaissance 20. Düsseldorf: Droste Verlag, I99 I.

Barber, Malcolm. The Crusader States. New Haven-London: Yale University Press, 20 I 2. Barber, Malcolm. The New Knighthood: A History of the Order of the Temple. Cambridge: Cambridge University Press, I 994.

Burgtorf, Jochen. The Central Convent of Hospitallers and Templars: History, Organization, and Personnel (IOgg/II20-I3IO). History of Warfare 50. Leiden-Boston: Brill, 2008. 
Burgtorf, Jochen. "Die Herrschaft der Johanniter in Margat im Heiligen Land." In Die Ritterorden als Träger der Herrschaft: Territorien, Grundbesitz und Kirche, herausgegeben von Roman Czaja und Jürgen Sarnowsky, 27-57. Ordines Militares. Colloquia Torunensia Historica XIV. Toruń: Wydawnictwo Uniwersytetu Mikołaja Kopernika, 2007.

Burgtorf, Jochen.'The Hospitaller Lordship of Margat." In East and West in the Medieval Eastern Mediterranean II: Antioch from the Byzantine Reconquest until the End of the Crusader Principality. Acta of the congress held at Hernen Castle (the Netherlands) in May 2006, herausgegeben von Krijnie Ciggaar und Victoria van Aalst, I I -50. Orientalia Lovaniensia Analecta I 99. Leuven: Peeters Press, 2013.

Burgtorf, Jochen. "Die Templer auf Ruad (1 300-1 302)." Ordines Militares Colloquia Torunensia Historica. Yearbook for the Study of the Military Orders 16 (20 I I) (Die Ritterorden in Umbruchs-und Krisenzeiten / The Military Orders in Times of Change and Crisis): 63-92.

Claverie, Pierre-Vincent. “Tortose.” In Prier et combattre: Dictionnaire européen des ordres militaires au Moyen Age, herausgegeben von Nicole Bériou und Philippe Josserand, 92 I. Paris: Librairie Arthème Fayard, 2009.

Demurger, Alain. Vie et mort de l'ordre du Temple: II20-1314. Paris: Éditions du Seuil, I 993, 3. Auflage.

Deschamps, Paul. La défense du comté de Tripoli et de la principauté d'Antioche: Étude historique, géographique, toponymique et monumentale, Texte. Les châteaux des Croisés en Terre Sainte 3, Institut Français d'Archéologie de Beyrouth, Bibliothèque Archéologique et Historique 90. Paris: Librairie Orientaliste Paul Geuthner, I 973.

Eck, Thomas. Die Kreuzfahrerbistümer Beirut und Sidon im I2. und I3. Jabrbundert auf prosopographischer Grundlage. Kieler Werkstücke, Reihe C: Beiträge zur europäischen Geschichte des frühen und hohen Mittelalters 3. Frankfurt am Main: Peter Lang, 2000.

Edbury, Peter W., und John Gordon Rowe. William of Tyre: Historian of the Latin East. Cambridge Studies in Medieval Life and Thought, 4. Serie. Cambridge: Cambridge University Press, 1988.

Ehlers, Axel. Die Ablasspraxis des Deutschen Ordens im Mittelalter. Quellen und Studien zur Geschichte des Deutschen Ordens 64. Marburg: N. G. Elwert Verlag, 2007.

Fedalto, Giorgio. La Chiesa Latina in Oriente. Bd. I. Studi religiosi 3. 2. Auflage. Verona: Casa Editrice Mazziana, I 98 I.

Fedalto, Giorgio. La Chiesa Latina in Oriente. Bd. II. Hierarchia Latina Orientis. Studi religiosi 3. Verona: Casa Editrice Mazziana, 1976.

Folda, Jaroslav. Crusader Art in the Holy Land, from the Third Crusade to the Fall of Acre, II 87-I29I. Cambridge: Cambridge University Press, 2005.

Forey, Alan. The Military Orders: From the Twelfth to the Early Fourteenth Centuries. New Studies in Medieval History. Basingstoke-London: Macmillan, I 992. 
Gertwagen, Ruthy. “Acre.” In Prier et combattre: Dictionnaire européen des ordres militaires au Moyen Age, herausgegeben von Nicole Bériou und Philippe Josserand, 48-50. Paris: Librairie Arthème Fayard, 2009.

Hamilton, Bernard. The Latin Church in the Crusader States: The Secular Church. London: Variorum Publications Ltd., I 980.

Hiestand, Rudolf. "Die Anfänge der Johanniter." In Die geistlichen Ritterorden Europas, herausgegeben von Josef Fleckenstein und Manfred Hellmann, 3 I-80. Vorträge und Forschungen XXVI. Sigmaringen: Jan Thorbecke Verlag, I 980.

Hiestand, Rudolf. “Templer- und Johanniterbistümer und -bischöfe im Heiligen Land." In Ritterorden und Kirche im Mittelalter, herausgegeben von Zenon Hubert Nowak, I 43-I62. Ordines Militares. Colloquia Torunensia Historica IX. Toruń: Wydawnictwo Uniwersytetu Mikołaja Kopernika, 1997.

Hiestand, Rudolf. "Zum Problem des Templerzentralarchivs." Archivalische Zeitschrift 76 (1 980$):$ I $7-38$.

Jacoby, David. “Acre.” In The Crusades: An Encyclopedia. Bd. I, herausgegeben von Alan V. Murray, 9-12. Santa Barbara: ABC Clio, 2006.

Kennedy, Hugh. Crusader Castles. Cambridge: Cambridge University Press, I 994.

Kennedy, Hugh. “Tortosa (Syria).” In The Crusades: An Encyclopedia. Bd. IV, herausgegeben von Alan V. Murray, i i 86. Santa Barbara: ABC Clio, 2006.

Kirstein, Klaus-Peter. Die lateinischen Patriarchen von Jerusalem: Von der Eroberung der Heiligen Stadt durch die Kreuzfahrer Iogg bis zum Ende der Kreuzfahrerstaaten I29I. Berliner Historische Studien 35, Ordensstudien XVI. Berlin: Duncker \& Humblot, 2002.

Krämer, Thomas. Dämonen, Prälaten und gottlose Menschen: Konflikte und ibre Beilegung im Umfeld der geistlichen Ritterorden. Vita regularis, Ordnungen und Deutungen religiosen Lebens im Mittelalter, Abhandlungen 64. Berlin: Lit Verlag, 20 I 5.

Lewis, Kevin James. The Counts of Tripoli and Lebanon in the Twelfth Century: Sons of Saint-Gilles. Rulers of the Latin East. London-New York: Routledge, 20 I 7.

Löffler, Anette. "Elisabeth in der Liturgie des Deutschen Ordens." In Elisabeth von Thüringen und die neue Frömmigkeit in Europa, herausgegeben von Christa Bertelsmeier-Kierst, I 33- I 49. Kulturgeschichtliche Beiträge zum Mittelalter und zur frühen Neuzeit I. Frankfurt am Main: Peter Lang, 2008.

Lotan, Shlomo. The Teutonic Order in the Latin Kingdom ofJerusalem: The Development of the Teutonic Military Order IIgo-I309, Mutual Relations between the Latin East and Europe. Tel Aviv: Ofir Bikurim, 20 I 2 [Hebräisch].

Luttrell, Anthony. “The Hospitallers' Early Statutes." Revue Mabillon I 4 (2003): 9-22.

Luttrell, Anthony. “The Hospitallers' Early Written Records." In The Crusades and Their Sources: Essays Presented to Bernard Hamilton, herausgegeben von John France und William G. Zajac, I 35-I 54. Aldershot: Ashgate, 1998.

Major, Balázs. Medieval Rural Settlements in the Syrian Coastal Region (I 2th and I 3 th Centuries). Archaeolingua: Central European Archaeological Heritage Series 9. Oxford: Archaeopress Archaeology, 2015. 
Major, Balázs, und Éva Galambos. "Archaeological and Fresco Research in the Castle Chapel at al-Marqab: A Preliminary Report on the Results of the First Seasons." In The Military Orders. Bd. 5, Politics and Power, herausgegeben von Peter W. Edbury, 23-47. Farnham: Ashgate, 2012.

Mayer, Hans Eberhard. Die Kanzlei der lateinischen Könige von Jerusalem. Bd. I-II. Monumenta Germaniae Historica, Schriften 40. Hannover: Hahnsche Buchhandlung, 1996.

Militzer, Klaus. Von Akkon zur Marienburg: Verfassung, Verwaltung und Sozialstruktur des Deutschen Ordens, IIgo-I309. Quellen und Studien zur Geschichte des Deutschen Ordens 56, Veröffentlichungen der Internationalen Historischen Kommission zur Erforschung des Deutschen Ordens 9. Marburg: N. G. Elwert Verlag, I 999.

Milthaler, Frank. Die Großgebietiger des Deutschen Ritterordens bis 1440. Schriften der Albertus-Universität, Geisteswissenschaftliche Reihe 26. Königsberg-Berlin: OstEuropa-Verlag, I 940.

Nicholson, Helen. Templars, Hospitallers and Teutonic Knights: Images of the Military Orders, II28-I29I. Leicester: Leicester University Press, I 993.

Polok, Margarete. "Ein Kreuzfahrerkloster unter strukturellen und prosopographischen Aspekten: Die Abtei auf dem Berge Thabor im i 2. und I 3. Jahrhundert." Staatsexamensarbeit, Heinrich-Heine-Universität Düsseldorf, I 995 [Maschinenschrift].

Pringle, Denys. The Churches of the Crusader Kingdom of Jerusalem: A Corpus. Bd. I. A-K (excluding Acre and Jerusalem). Cambridge: Cambridge University Press, I 993.

Pringle, Denys. The Churches of the Crusader Kingdom ofJerusalem: A Corpus. Bd. IV. The Cities of Acre and Tyre (with Addenda and Corrigenda to Volumes I-III). Cambridge: Cambridge University Press, 2009.

Pringle, Denys. "The Military Orders in the Cities of the Holy Land." In Les Ordres militaires dans la ville médiévale, Actes du colloque international de Clermont-Ferrand, 26-28 mai 2010, herausgegeben von Damien Carraz, 79-95. Collection Histoires croisées. Clermont-Ferrand: Presses Universitaires Blaise-Pascal, 20 I 3.

Pringle, Denys. Secular Buildings in the Crusader Kingdom of Jerusalem: An Archaeological Gazetteer. Cambridge: Cambridge University Press, 1997.

Prutz, Hans. Die Geistlichen Ritterorden: Ihre Stellung zur kirchlichen, politischen, gesellschaftlichen und wirtschaftlichen Entwicklung des Mittelalters. Berlin: Ernst Siegfried Mittler und Sohn, I 908 (Nachdruck: Berlin: Haude \& Spenersche Verlagsbuchhandlung, i 977).

Rheinheimer, Martin. Das Kreuzfahrerfürstentum Galiläa. Kieler Werkstücke, Reihe C: Beiträge zur europäischen Geschichte des frühen und hohen Mittelalters I. Frankfurt am Main: Peter Lang, I 990.

Riley-Smith, Jonathan. The Knights Hospitaller in the Levant, c.1070-1309. Basingstoke-New York: Palgrave Macmillan, 20 I 2.

Riley-Smith, Jonathan. The Knights of St. John in Jerusalem and Cyprus c.I050-I3Io. London: Macmillan/St. Martin’s Press, i 967. 
Riley-Smith, Jonathan. Templars and Hospitallers as Professed Religious in the Holy Land. The Conway Lectures in Medieval Studies 2008. Notre Dame: University of Notre Dame Press, 20 io.

Röhricht, Reinhold. Geschichte des Königreichs Jerusalem (IIOo-I29I). Innsbruck: Verlag der Wagner'schen Universitäts-Buchhandlung, i 898 (Nachdruck: Amsterdam: Verlag M. Hakkert, i 966).

Thorau, Peter. The Lion of Egypt: Sultan Baybars I and the Near East in the Thirteenth Century. Übersetzt von Peter M. Holt. London-New York: Longman, I 992.

Thorau, Peter. “Tortosa.” In Lexikon des Mittelalters. Bd. VIII, Stadt (Byzantinisches Reich) bis Werl, 884-885. Stuttgart-Weimar: Verlag J. B. Metzler, I 999; Erstveröffentlichung: I $996-1997$.

Toomaspoeg, Kristjan. “The Military Orders and the Diocesan Bishops: A Pragmatic Relationship." Ordines Militares Colloquia Torunensia Historica. Yearbook for the Study of the Military Orders 23 (20 I 8): 93- I 25.

Whalen, Brett Edward. "Hebron." In The Crusades: An Encyclopedia. Bd. II, herausgegeben von Alan V. Murray, 563-564. Santa Barbara: ABC Clio, 2006. 